\title{
The atmospheric branch of the hydrological cycle over the Indus, Ganges, and Brahmaputra river basins
}

\author{
Rogert Sorí $^{1}$, Raquel Nieto ${ }^{1,2}$, Anita Drumond ${ }^{1}$, Sergio M. Vicente-Serrano ${ }^{3}$, and Luis Gimeno ${ }^{1}$ \\ ${ }^{1}$ Environmental Physics Laboratory (EphysLab), Universidade de Vigo, Ourense, 32004, Spain \\ ${ }^{2}$ Department of Atmospheric Sciences, Institute of Astronomy, Geophysics and Atmospheric Sciences, \\ University of SãoPaulo, São Paulo, 05508-090, Brazil \\ ${ }^{3}$ Instituto Pirenaico de Ecología, Consejo Superior de Investigaciones Científicas (IPE-CSIC), \\ Zaragoza, 50059, Spain
}

Correspondence: Rogert Sorí (rogert.sori@uvigo.es)

Received: 29 June 2017 - Discussion started: 24 July 2017

Revised: 10 October 2017 - Accepted: 26 October 2017 - Published: 15 December 2017

\begin{abstract}
The atmospheric branch of the hydrological cycle over the Indus, Ganges, and Brahmaputra river basins (IRB, GRB, and BRB respectively) in the South Asian region was investigated. The 3-dimensional model FLEXPART v9.0 was utilized. An important advantage of this model is that it permits the computation of the freshwater budget on air parcel trajectories both backward and forward in time from 0.1 to $1000 \mathrm{hPa}$ in the atmospheric vertical column. The analysis was conducted for the westerly precipitation regime (WPR) (November-April) and the monsoonal precipitation regime (MPR) (May-October) in the period from 1981 to 2015. The main terrestrial and oceanic climatological moisture sources for the IRB, GRB, and BRB and their contribution to precipitation over the basins were identified. For the three basins, the most important moisture sources for precipitation are (i) in the continental regions, the land masses to the west of the basins (in this case called western Asia), the Indian region (IR), and the basin itself, and (ii) from the ocean, the utmost sources being the Indian Ocean (IO) and the Bay of Bengal (BB), and it is remarkable that despite the amount of moisture reaching the Indus and Ganges basins from land sources, the moisture supply from the IO seems to be first associated with the rapid increase or decrease in precipitation over the sources in the MPR. The technique of the composites was used to analyse how the moisture uptake values spatially vary from the sources (the budget of evaporation minus precipitation $(E-P)$ was computed in a backward experiment from the basins) but during the pre-onset and pre-demise dates of the monsoonal rainfall over each basin; this confirmed that
\end{abstract}

over the last days of the monsoon at the basins, the moisture uptake areas decrease in the IO. The Indian region, the Indian Ocean, the Bay of Bengal, and the basins themselves are the main sources of moisture responsible for negative (positive) anomalies of moisture contribution to the basins during composites of driest (wettest) WPR and MPR.

\section{Introduction}

Research on the hydrological cycle in the Asian region has been extensive, which is mainly because of the strong influence of the Asian summer monsoon (ASM), which develops a crucial role in moisture transport and the supply of precipitation in this region (Webster, 2006). The ASM system has three different but inter-related components: South Asian monsoon (SAM), South East Asian monsoon (SEAM), and east Asian monsoon (EAM) (Janowiak and Xie, 2003). The Indian summer monsoon (ISM) is one of the most studied phenomena and is part of the SAM. It develops in response to the large thermal gradients between the warm Asian continent to the north and the cooler Indian Ocean to the south (Slingo, 1999). Solar heating is considered a fundamental driver of all of the monsoon systems. Heating of the Tibetan Plateau leads to increased ISM rainfall via enhancement of the cross-equatorial circulation and a concurrent strengthening of both the Somali jet and westerly winds that bring moisture to southern India (Rajagopalan and Molnar, 2013). Surface heating over the plateau plays a role in producing cy- 
clonic vorticity in the shallow lower layer but negative vorticity in the deep upper layers through atmospheric thermal adaptation (Yanai and Wu, 2006; Song et al., 2010). The satellite and conventional observations support an alternative hypothesis, which considers the monsoon as a manifestation of seasonal migration of the inter-tropical convergence zone (ITCZ) (Gadgil, 2003). Understanding and predicting the variability of the Indian monsoon is extremely important for the well-being of over 1 billion people and the diverse flora and fauna inhabiting the region (Gadgil, 2003).

The monsoonal regimes in India, tropical Africa, and North America are provided with moisture from a large number of regions (Gimeno et al., 2012). According to Misra et al. (2012), instead of rainfall, evaporative sources (of the ISM) may be a more appropriate metric to observe the relationship between the seasonal monsoon strength and intraseasonal activity. It is worth mentioning that the precipitation over any area of land comes from the moisture already available in the local atmosphere, the convergence of the moisture advected into the region by the winds, and the supply by evaporation from within the same region (Gong and Eltahir, 1996; Trenberth, 1999). The atmospheric branch of the hydrological cycle consists of the atmospheric transport of water, which is mainly in the vapour phase (Peixoto and Oort, 1992), and plays a crucial role in understanding the bridge between evaporation in the sources and precipitation over remote regions. Indeed, the identification of moisture sources for precipitation constitutes an important feature to understand the further mechanisms associated with rainfall variability (Gimeno et al., 2012), and it has become a major research tool in the analysis of extreme events (e.g. floods and droughts) (Gimeno, 2014).

Numerous studies (e.g. Drumond et al., 2011; Misra and DiNapoli, 2014; Ordoñez et al., 2012; Pathak et al., 2017) have determined the origin of moisture that contributes to precipitation in Asia. Ordoñez et al. (2012) confirmed the key action of the Somali low-level jet bringing moisture from the Arabian Sea and the Indian Ocean during the boreal summer and documented the importance of recycling as the main water vapour source in the winter for this region. Chen et al. (2012) identified and quantified the origin (destination) of moisture and air mass transported to (from) the Tibetan Plateau from June to August, and Pathak et al. (2017) made an extensive study of the role of oceanic and land moisture sources during the summer monsoon in India to confirm the strong land-ocean-atmosphere interactions. To determine the evaporative sources of the SEAM region, Misra and DiNapoli (2014) found that the largest evaporative source for the rainy season in the SEAM region came from the local land-based evaporation and the seas in the immediate vicinity. Tuinenberg et al. (2012) applied a water trajectory model to investigate the moisture recycling rates over the Ganges River basin (GRB) and confirmed that a large influx of moisture from the Indian Ocean dominates precipitation. The recycling of precipitation helps in defining the role of land-atmosphere interactions in the regional climate (Bisselink and Dolman, 2008). The Indus River basin (IRB) is located in the north-west of India. Utilizing stable isotope measurements, Karim and Veizer (2002) determined that the predominant moisture sources for the IRB were located in a closed basin such as the Mediterranean or other inland seas. Together, the IRB, the Ganges River basin (GRB), and the Brahmaputra River basin (BRB) are the largest Asian river basins and occupy a large part of the Indo-Gangetic plain. In these basins, the importance of the basin itself in providing moisture has been previously proven (COLA, 2017).

Nevertheless, due to the complex hydrological cycle over the Indo-Gangetic plain, this region is quite unique compared to the rest of the world and the ASM plays a crucial role. In this region, the moisture source identification and evaluating their role in the moisture contribution for a target region are fundamental for understanding the nature of the precipitation in it. For these reasons, the aim of this work was to investigate the atmospheric branch of the hydrological cycle over the Indus, Ganges, and Brahmaputra river basins. This was done first by identifying the main seasonal oceanic and terrestrial moisture sources for each basin and later quantifying their contribution to precipitation over the basins. This analysis will allow determination of the role of the sources during different precipitation regimes, specifically for the rainfall associated with the monsoon onset and demise and for dry and wet conditions over the basins. Different criteria have been used in the past to define the onset and retreat over different monsoon regions and even over different parts of the same monsoon (Zeng and Lu, 2004). Taniguchi and Koike (2006) argue that the rapid enhancement of the wind speed related well with the abrupt beginning of the rainy season, and it represents a clear transition in atmospheric conditions or the beginning of ISM.

\subsection{Study area}

The study was performed for the Indus, Ganges, and Brahmaputra river basins, which are located in South and South East Asia (Fig. 1). The Ganges is the largest river basin in the Indian sub-continent followed by the IRB and the BRB; all of these river basins are densely populated and represent a complete range of landscapes and ecosystems on which the major agricultural activities rely (Davis, 2003; Hossen, 2015; Tare et al., 2015; Mahanta et al., 2014; Laghari et al., 2012).

Two main climate systems drive the annual precipitation over the basins, the ASM in summer and the western disturbances (WDs) during the winter months (Hasson et al., 2014). It provides some feature of a bimodal precipitation regime: the monsoonal precipitation regime (MPR) for MayOctober and the westerly precipitation regime (WPR) for November-April (Hasson et al., 2016, 2014). In the MPR, the summer monsoon has a key role in the hydro-climatology of Asia. Even the sub-seasonal river discharge is found to be 


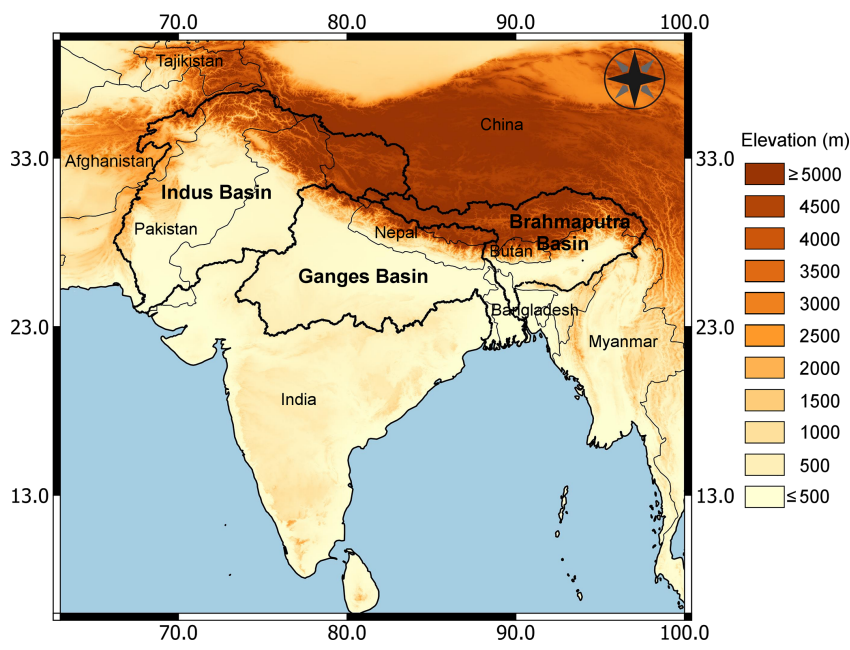

Figure 1. The geographic location and boundaries of the Indus, Ganges, and Brahmaputra river basins from Hasson et al. (2013), and the elevation from the Hydrosheds project (Lehner et al., 2008).

strongly tied to the monsoon intraseasonal cycle, which results in a near-in-phase timing of the Ganges and Brahmaputra discharge (Jian et al., 2009), whereas the WDs during the WPR are important synoptic weather systems responsible for almost one-third of the annual precipitation over the northern Indian region and most of the cold season precipitation (Dimri el al., 2015). During the boreal winter, the meltwater is extremely important in the Indus basin and is also important for the Brahmaputra basin, but plays only a modest role for the Ganges (Immerzeel et al., 2010). Indeed, the IRB irrigation system (IBIS) is the largest irrigation system in the world (Qureshi, 2011; Laghari et al., 2012). From a geographic and climatologic perspective, the IRB is at a transition between the monsoon system in the east and the Mediterranean system in the west (Karin and Veizer, 2002).

\section{Materials and methods}

\subsection{Study period}

The study was conducted for the period from 1981 to 2015 and took into account the criterion of Hasson et al. (2016). These authors considered two hydro-climatological periods of the year: May-October, which was named as "monsoonal precipitation regime" and hereafter MPR, and NovemberApril, the "westerly precipitation regime", which is hereafter referred to as WPR, to study the seasonal cycle of the water balance over the Indus, Ganges, and Brahmaputra River basin. The annual cycle of the precipitation $(P)$, evaporation $(E)$ and potential evapotranspiration (PET) over the basins are assessed. Monthly data of $P$ and $E$ belong to CRU 3.24.01 (Harris et al., 2014) and from monthly means of daily forecast accumulations from ERA-Interim (ERA-I) reanalysis (Dee et al., 2011).

\subsection{The Lagrangian approach}

The 3-d Lagrangian model FLEXPART v9.0, which was developed by Stohl and James (2004, 2005), was utilized to identify the moisture sources for the IRB, GRB, and $\mathrm{BRB}$ and investigate their role in the atmospheric water balance over the basins. The model was executed considering the atmosphere is homogeneously divided into approximately 2.0 million uniformly distributed parcels. The parcels were advected backward and forward in time using the 3dimensional winds field from the ERA-I reanalysis (Dee et al., 2011), which is a mechanism described by Eq. (1):

$\mathrm{d} x / \mathrm{d} t=v[x(t)]$,

where $x$ is the position of the parcel and $v[x(t)]$ is the wind speed interpolated in space and time. For each parcel, a constant mass $(m)$ was considered. By interpolating $q$ to $x(t)$, the net rate of change of the water vapour content of a particle is computed by Eq. (2), where $e$ represents the moisture gain (through evaporation from the environment) and $p$ the moisture loss (e.g. through precipitation).

$(e-p)=m(\mathrm{~d} q / \mathrm{d} t)$

Integrating $(e-p)$ in all of the atmospheric vertical column, we obtain a diagnosis of the surface freshwater flux, which is represented by $(E-P)$ (Stohl and James, 2004) in Eq. (3), where $K$ is the number of particles residing over an area $A$.

$E-P \approx \frac{\sum_{k=1}^{k}(e-p)}{A}$

To calculate the freshwater flux, the average time residence of the water vapour in the atmosphere was considered, and it was set to 10 days according to Eltahir and Bras (1996) and Numaguti (1999). The calculus conducted in the air masses, tracked backward in time from over each basin, permitted identification of those regions where air masses gained and lost humidity before arriving at the basins and thus enabled the identification of the moisture sources of the regions. This indicates that those regions where $(E-P)>0$ are considered moisture sources, whereas the opposite $(E-P)<0$ are moisture sinks. FLEXPART needs the following 3-dimensional fields: horizontal and vertical wind components, temperature, and specific humidity in the ECMWF vertical hybrid coordinate system. The model also needs the two-dimensional fields: surface pressure, total cloud cover, $10 \mathrm{~m}$ horizontal wind components, $2 \mathrm{~m}$ temperature and dew point temperature, large-scale and convective precipitation, sensible heat flux, east-west and north-south surface stress, topography, land-sea mask, and sub-grid standard deviation of the topography. To run FLEXPART, it utilized the ERA-I reanalysis dataset (Dee et al., 2011) at 6 $\mathrm{h}$ intervals (00:00, 06:00, 12:00, and 18:00 UTC) and at a resolution of $1^{\circ}$ in latitude and longitude considering 61 vertical levels from 0.1 to $1000 \mathrm{hPa}$. 
The use in ERA-I of 4D-Var data assimilation contributed to better time consistency than the 3D-Var used in ERA-40. However, the agreement between the global tendencies of mass and total column water vapour (TCWV) and $(E-P)$ is not very good in ERA-I, but it is still much better than for ERA-40 (Berrisford et al., 2011).

Sebastian et al. (2016) found a huge uncertainty in the estimates of $(P-E)$ over South Asia, when computed from different reanalyses, but recommend using atmospheric budget for computation of water availability in terms of $(P-E)$ rather than based on individual values of $P$ and $E$. We also consider that in the state-of-the-science discussion on three reanalyses (ERA-I, MERRA, and CFRS), Lorenz and Kunstmann (2012) found that the ERA-I shows both a comparatively reasonable closure of the terrestrial and atmospheric water balance and a reasonable agreement with the observation datasets. These findings support the use of ERA-I datasets for running FLEXPART in order to reduce the uncertainty in this study. In the same way, the vertically integrated northward and eastward moisture flux data to calculate the vertically integrated moisture flux (VIMF) and its divergence belong to the ERA-I reanalysis with a resolution of $1^{\circ} \times 1^{\circ}$. Computing the $(P-E)$ directly from atmospheric budget with divergence of moisture flux for different reanalyses improved correlation with observed values of $(P-E)$ according to Sebastian et al. (2016) results, and we will take that into consideration for future studies.

Detailed information regarding FLEXPART functionalities can be found in Stohl and James (2004, 2005). Concerning the limitations of the method, Eq. (3) can diagnose $(E-P)$ but not $E$ or $P$ individually according to Stohl and James (2004). These authors also argue that along with individual trajectories, $q$ fluctuations can occur for nonphysical reasons (e.g. because of $q$ interpolation or trajectory errors), which is a limitation that is partly compensated for among the many particles in an atmospheric column over the target area. This approach has been used in numerous studies with the main purpose of characterizing the atmospheric branch of the hydrological cycle in different regions, e.g. in western and southern India (Ordoñez et al., 2012), the Sahel (Nieto et al., 2006), China (Drumond et al., 2011; Huang and Cui, 2015), the Mississippi River basin (Stohl and James, 2005), the Amazon River basin (Drumond et al., 2014), and Central America (Durán-Quesada et al., 2010). On a global scale, FLEXPART has been implemented to identify the main oceanic and continental moisture sources for precipitation (Gimeno et al., 2012) as well as a catalogue of moisture sources for two sets of continental climatic regions (Castillo et al., 2014). The main advantage of FLEXPART is that it permits the tracking of air masses backward and forward in time and calculates along the trajectories the water balance in the atmospheric column.

For delimiting the most evaporative regions in the moisture sources, some authors (e.g. Drumond et al., 2014, 2016) have used a threshold (a percentile value) to define the bound- aries. In this work, we apply the same technique; the value of the 90th percentile in the $(E-P)>0$ values integrated over 10 days of transport was considered to delimit the sources. An exception in this work was that each river basin was considered a source region; which permitted the study of the role of each one and the balance of $(E-P)$ on them.

Once the moisture sources were delimited, a forwardin-time analysis was implemented to determine the contribution of each source to the precipitation over the basins (when $(E-P) i 10<0)$. This analysis allowed us to later perform a seasonal correlation analysis between the data of $(E-P) i 10<0$ with $P$ and PET to determine the best linear relationships.

\subsection{Selection of pre-onset and pre-demise monsoonal dates over the basins}

Here, we address the spatial variability of the moisture uptake for the basins during composites of dates associated with the pre-onset and demise of the Indian monsoon over the basins. To determine the day on which the increase in rainfall indicates the beginning of the monsoon involvement for each basin, we utilized the method proposed by Noska and Misra (2016). This method is based on daily cumulative anomalies $\left(C^{\prime} m\right)$ of the average precipitation for each basin along the year and according to Eqs. (4) and (5).

$$
\begin{aligned}
& C^{\prime} m(i)=\sum_{n=1}^{i}[D m(n)-C], \\
& C=\frac{1}{M N} \sum_{m=1}^{M} \sum_{n=1}^{N} D(m, n),
\end{aligned}
$$

where $D(m, n)$ is the daily basin rainfall for day $n$ of year $m$, and $C$ is the climatology of the annual mean of the precipitation at each basin over $N$ (=365 or 366) days for $M$ years. The onset is then defined as the day after $C^{\prime} m$ reaches its absolute minimum value, but from May onward when the MPR is defined. When applied, this criterion avoids the selection of a false date that could arise and be associated with the previous winter precipitation. Similarly, the demise is considered the day when $C^{\prime} m$ reaches the maximum value after the onset. For this analysis, it was necessary to use a series of precipitation on a daily basis over an extended period of the study, 1981-2015. For our goal, we preferred to utilize the observational precipitation datasets from the Climate Hazards Group InfraRed Precipitation with Station data (CHIRPS; Chris et al., 2015) which has the advantage of being based on a combination of satellite and rain gauge data. At least, an analysis on a monthly scale for June-August by Ceglar et al. (2017) revealed that out of the four reanalyses (ERA-I, ERA-I/Land, AgMERRA (an agricultural version of MERRA), and JRA-55), all of them show more uniformly distributed monthly precipitations over monsoon Asia 
when compared to CHIRPS than APHRODITE (Yatagai et al., 2009).

Different criteria have been used in the past to define onset and retreat over different monsoon regions and even over different parts of the same monsoon (Zeng and Lu, 2004). Taniguchi and Koike (2006) argue that the rapid enhancement of the wind speed related well with the abrupt beginning of the rainy season and it represents a clear transition in atmospheric conditions or the beginning of ISM. To determine the onset and demise dates, we applied an objective index to the basins from Noska and Misra (2016), which was previously adapted for the Asian monsoon region in Misra and DiNapoli (2014) and builds upon the index proposed by Liebmann et al. (2007). The analysis is based on the cumulative anomalies of daily rainfall averaged (see Eqs. 4 and 5) over the basins and is permitted to identify the date associated with rainfall increase because of the monsoon onset (the day after the minimum accumulated rainfall anomalies) and demise (the day of the maximum accumulated rainfall). According to Noska and Misra (2016), this index is capable of representing the annual rainfall variability across the region and thus must be adequate for our target regions.

\subsection{Identification of dry and wet conditions}

To identify dry and wet conditions in the basins, the Standardised Precipitation-Evapotranspiration Index (SPEI) (Vicente-Serrano et al., 2010) was used. SPEI is based on a standardization of the climatic water balance (Precipitation $P$ - minus atmospheric evaporative demand - AED), which is computed on different timescales. The data of $P$ and AED were obtained from CRU TS v.3.24.01 (Harris et al., 2014). The concept of the PET has proven to be inappropriate because the evaporation climatic demand is not only linked to the climate but also to the type of the evaporative surface, and some authors have adopted a more suitable term: evaporative atmospheric demand (Katerji and Rana, 2011; McVicar et al., 2012). However, we will keep the term "PET" throughout the text as the original data are named by the source. We calculated the 6-month SPEI to assess drought severity conditions on the three basins since this timescale adapts to the time period of the two main hydro-climatological seasons over the basins (WPR and MPR). Thus, the 6-month SPEI at the end of April (October) characterized the water balance for the WPR (MPR). According to the criterion of McKee et al. (1993), we used an SPEI threshold of \pm 1.5 to identify severe and extreme dry $(-1.99$ to $-1.5 ; \leq-2.0$ respectively) and wet ( 1.5 to $1.99 ; \geq 2.0$ respectively) conditions.

It is important to emphasize that we have used precipitation data from different sources, which is not consistent with the FLEXPART input data from ERA-I reanalysis. Nevertheless, it makes it possible to avoid the any possible co-linearity when analysing different hydro-meteorological process.

\section{Results and discussion}

\subsection{The precipitation and evaporation over the basins}

The mean annual cycle of the $P, E$, and PET over the Indus, Ganges, and Brahmaputra basins appears in Fig. 2. For the three basins, the maximum $P$ occurs during the summer months. It can be observed that monthly $P$ values from ERAI tend to be slightly greater than those computed from CRU, but the annual cycle is the same. These differences are best appreciated in the annual cycle of $P$ over the BRB. In the IRB, the $P$ annual cycle is characterized by two maximum peaks in February-March and July-August (Fig. 2a). The $E$ approximately follows this cycle but with lower values. In this basin, the PET remains higher than the $P$ and $E$ across the year; in fact, Cheema (2012) argue that the major part of this basin is dry and located in arid to semiarid climatic zones. Laghari et al. (2012) also found for the climatology from 1950 to 2000 that PET exceeds $P$ at the IRB across the year. PET is enhanced after maximum precipitation; maximum values occur in May-June. Over the GRB maximum $P$ occurs between May and October and is greater than over the IRB. The PET and $E$ annual cycles over this basin differ, and as expected, PET $>E$. The PET annual cycle is mainly like for the IRB. Indeed, both variables reflect close but different information. The $E$ annual cycle agrees with that obtained by Hasson et al. (2014) for the three river basins. Over the BRB, the monthly average precipitation both from CRU and ERA-I increases abruptly from March until a maximum $\left(>11.0 \mathrm{~mm} \mathrm{day}^{-1}\right)$ in July and later falls until a minimum is reached in December (Fig. 2c). The PET and $E$ are very close and do not surpass $4 \mathrm{~mm}$ day $^{-1}$ in the annual climatology. In particular, the PET annual cycle is notable for being lower than what was obtained for the IRB and GRB. The annual cycles of $P$ (from CRU and ERA-I) and $E$ for the IRB, GRB, and BRB follow the same annual cycle as those obtained by Hasson et al. (2014). These authors analysed the seasonality of the hydrological cycle over the same basins for the 20th century climate (1961-2000 period), utilizing PCMDI/CMIP3 general circulation models (GCMs) and observed precipitation data.

Tropical cyclones and weak disturbances contribute to monsoon rainfall. Among these systems, the most efficient rain-producing system (responsible for about half of the Indian summer monsoon rainfall) is known as the Indian monsoon depression (MD) which generally forms around Bay of Bengal and propagates westward or north-westward with a typical life span of 3 to 6 days (Ramage, 1971; Yoon and Huang, 2012). The change in the large-scale circulation, especially the converging atmospheric water vapour flux, is responsible for the MD modulation by the 30-60-day monsoon mode (Yoon and Huang, 2012). Over the Brahmaputra basin, the rainiest, heavy rainstorms are due to the shifting of the eastern end of the seasonal monsoon trough to the foothills of Himalayas in the north and the "break" monsoon situa- 


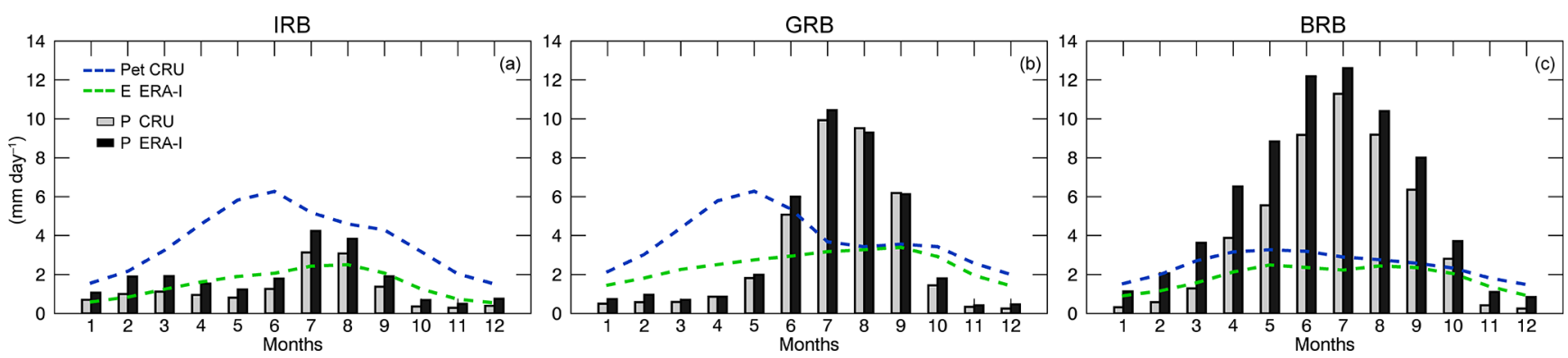

Figure 2. The 1981-2015 annual cycle of precipitation (gray, black bars from CRU and ERA-I, mm day ${ }^{-1}$ ) and potential evapotranspiration (blue line from CRU, mm day ${ }^{-1}$ ) and evaporation (green line from ERA-I, mm day ${ }^{-1}$ ) over the Indus (a), Ganges (b), and Brahmaputra (c) river basins from CRU 3.24.01.

tions during the monsoon season (Dhar and Nandargi, 2000). Summarizing, the BRB is wetter than the western GRB and IRB; this is because the monsoon rainfall dominates in the summer months in the eastern region and gets weaker on the western side with a time delay of a period of weeks (Hasson et al., 2014).

\subsection{Identification of moisture sources}

The climatological budget of $(E-P) i 10$ obtained in the backward track experiment of air masses residing over the three basins and the VIMF and its divergence appears in Fig. 3. The analysis was conducted for the WPR and MPR periods. In the first one, the most intense positive values (delimited by p90) in the pattern of $(E-P) i 10$ obtained for the IRB, are over the basin itself and they extend southwest until the Indian Ocean (IO) and East Africa (EA). High $(E-P) i 10>0$ values are also confined by the p90 (green line) to the west of the basin (hereafter western Asia; WA), the Persian Gulf (PG), the Red Sea (RS) and to the southeast occupying a major part of the Indian region (IR) and part of the Bay of Bengal (BB). In this season, the field of $(E-P) i 10$ obtained in the backward experiment from the GRB is very similar to the one obtained for the IRB, but the p90 is now extended to the east and even confines part of the East China Sea and South China Sea (CHS). Over the GRG itself, the highest values of $(E-P) i 10>0$ are observed. For the BRB in the pattern of $(E-P) i 10$, the line of p 90 is longitudinally extended from East Africa until the CHS and seems less intense than those previously obtained for the IRB and GRB. In this season, the prevalence of the divergence of the VIMF can be distinguished in almost all of the Indian regions except the northern parts of the IRB and the GRB and the western parts of the BRB, where they are overcome by the convergence of the VIMF. In the northern part of the basins, the VIMF is mainly to the east but over the Indian region is mainly to the south-west and is more intense over the Arabian Sea, which is a feature that is known to be linked to excessive latent heat fluxes and is related to both the anomalous meridional temperature gradient originated between the lands to the north of the Arabian Sea (and elsewhere) and the sea surface temperature (SST) at the Arabian Sea (Levine and Turner, 2012; Marathayil et al., 2013).

In the MPR, the pattern of $(E-P) i 10$ is more extended and intense than in the WPR (Fig. 3). In the backward experiment for the three basins it is commonly distinguished that the p90 line comprises a huge area in the western Indian Ocean and to the west of each basin. The moisture transport from the Indian Ocean crossing the Arabian Sea and penetrating into the continent is revealed by the VIMF; observational analysis shows strong monsoons depend on moisture fluxes across the Arabian Sea (Levine and Turner, 2012). According to Qiao et al. (2013), the inter-annual variation of the moisture source over the western-central south Indian Ocean is determined by the variation of both local precipitation and evaporation. Thus, the use of FLEXPART to assess the role of this region in moisture supply to the target regions could be an advantage. Previous regions that provided moisture for the basins in the East Asian region and the CHS are moisture sinks in this season in accordance with the VIMF convergence. To the east of the IRB, over the east of the GRB and over all of the BRB are moisture sinks. In these areas, the air masses lose humidity before they arrive at each basin, which is apparently because of the intense precipitation over this region associated with the Indian Monsoon.

To determine the different roles within the continental and oceanic moisture sources and taking into account the region where they are located, we made a separation for the WPR and MPR. The selected sources are shown through a schematic representation in Fig. 4. The regions shaded in colour represent the location and spatial extension of the most important moisture sources previously delimited using the p90 values and independently calculated for the $(E-P) i 10>0$ values for every basin and period (Fig. 3). The sources clearly divide the continental and oceanic zones where the budget of $(E-P) i 10$ was calculated earlier. The criterion adopted here permits the investigation of the role of continental and oceanic moisture sources according to their location. 


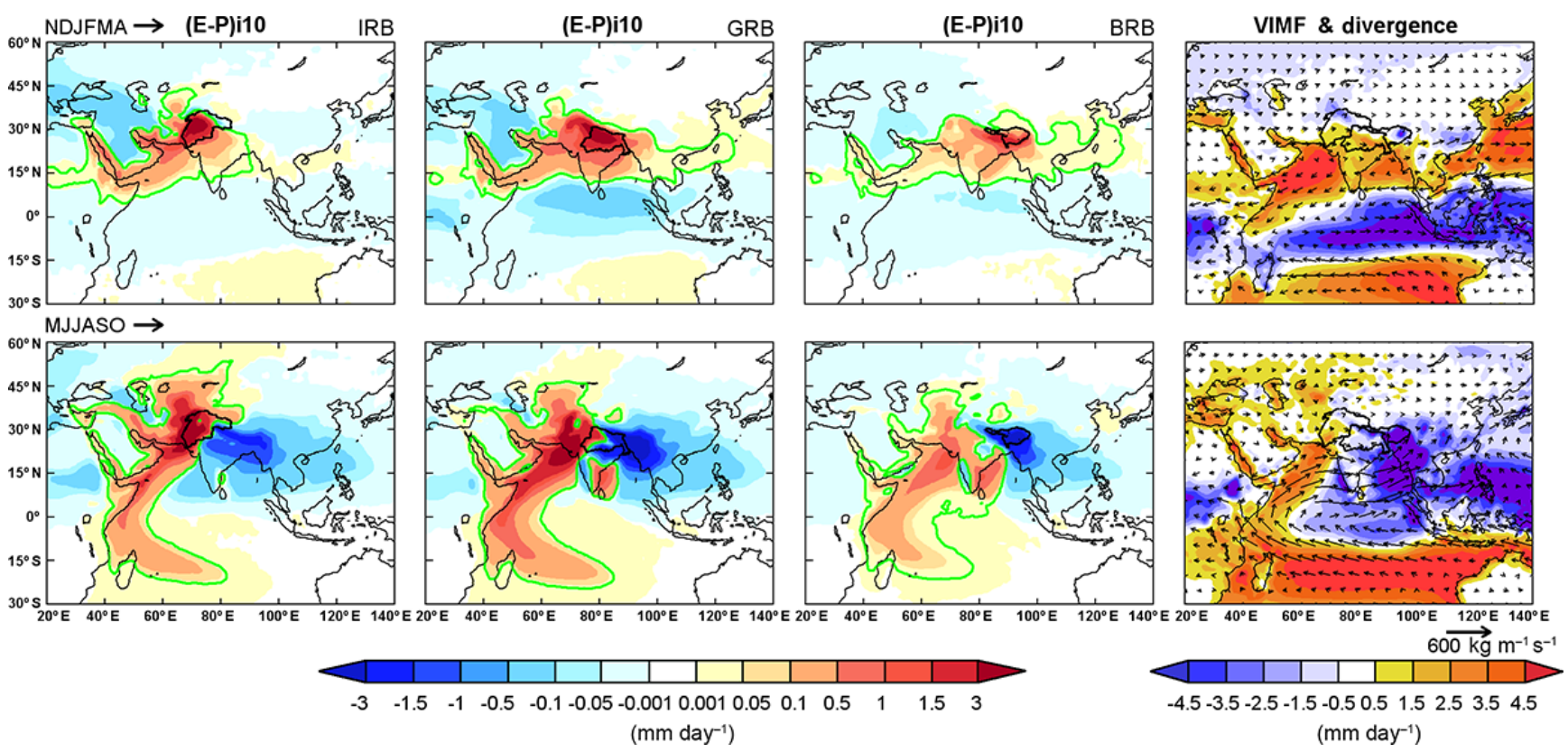

Figure 3. November-April (top) and May-October (bottom) $(E-P) i 10\left(\mathrm{~mm} \mathrm{day}^{-1}\right)$ backward integrated from the Indus, Ganges, and Brahmaputra river basins (contoured by a black line) (from FLEXPART) and vertically integrated moisture flux (VIMF) $\left(\mathrm{arrows} \mathrm{kg} \mathrm{m}^{-1} \mathrm{~s}^{-1}\right.$ ) and divergence of the VIMF (shaded, $\mathrm{mm} \mathrm{day}^{-1}$ ). The 90th percentile is represented by a green line. Period 1981-2015.

For the IRB in the WPR, the continental moisture sources were divided into East Africa (EA; also extending to the west over the Sahel), the Arabian Peninsula (AP) mainly around the coast, in Asia to the west of this basin (western Asia, WA), and the Indian region (IR) (Fig. 4a). The oceanic moisture sources are easily divided and cover a small part of the western Mediterranean Sea (MS), the whole Red Sea (RS), the Persian Gulf (PG), the Indian Ocean (IO; mostly in the Arabian Sea region), the Bay of Bengal (BB), and finally part of the Caspian Sea (CS). For the IRB in the WPR and MRP, the moisture sources almost remain in the same regions but change spatially because they are more extended in the MPR period with the exception of the IR and the BB, which are almost imperceptible (Fig. 4b). In the MPR the IO, which is extended to the south and south-east, is highlighted. With respect to the rest of the continental sources, the EA is confined to the east of the African continent but the WA increased its spatial extent to the east and north. Because of the relative similar location of the sources for the GRB (Fig. 4c and d) and BRB (Fig. 4e and f), we kept the names already utilized for classification of the IRB moisture sources. However, some new region may appear such as the CHS and centraleast Asia (CEA) during WPR, and a small moisture source to the north of the GRB and BRB, named central Asia (CA), in the MPR. In the same period, to the west of the BRB, we approximately divided the areas as previously classified for other basins as WA and IR. Ordoñez et al. (2012) also divided the evaporative regions obtained in a backward analysis from western and southern India, taking into account the well-known geographical regions. Pathak et al. (2017) also calculated the moisture contribution from oceanic and terrestrial sources for the ISM rainfall. However, in their method, the terrestrial sources were approximately selected based on the uniform climate sub-type of Köppen and the percentage of forest cover in the year 2000, while the oceanic sources were according to the VIMF. They considered divergent areas as the potential sources, whereas regions with high convergence were considered potential sink regions. Nevertheless, in our approach, moisture sources are considered those regions from where air masses uptake humidity before arrive to the basins.

\subsection{Role of continental and oceanic moisture sources}

\subsubsection{Budget of $(E-P)$}

The budget of $(E-P)$, over the 10-day cycles backward in time from each basin for the WPR and MPR and over the continental and oceanic regions and each basin separately, was quantified (Fig. 5). In the WPR, the $(E-P) i 10$ over the IRB itself is positive and greater than that obtained over the remaining continental and oceanic moisture sources (Fig. 5a). As seen in Fig. 2, the PET is greater than $P$ over the IRB in these periods, which indicates the prevalence of evaporative conditions in this basin. As the IRB is also a landbased source, the budget of $(E-P) i 10$ over the basin, together with the budget over the rest of the continental areas, reveals the importance of the continental moisture sources for the water supply to the IRB and is probably because of 

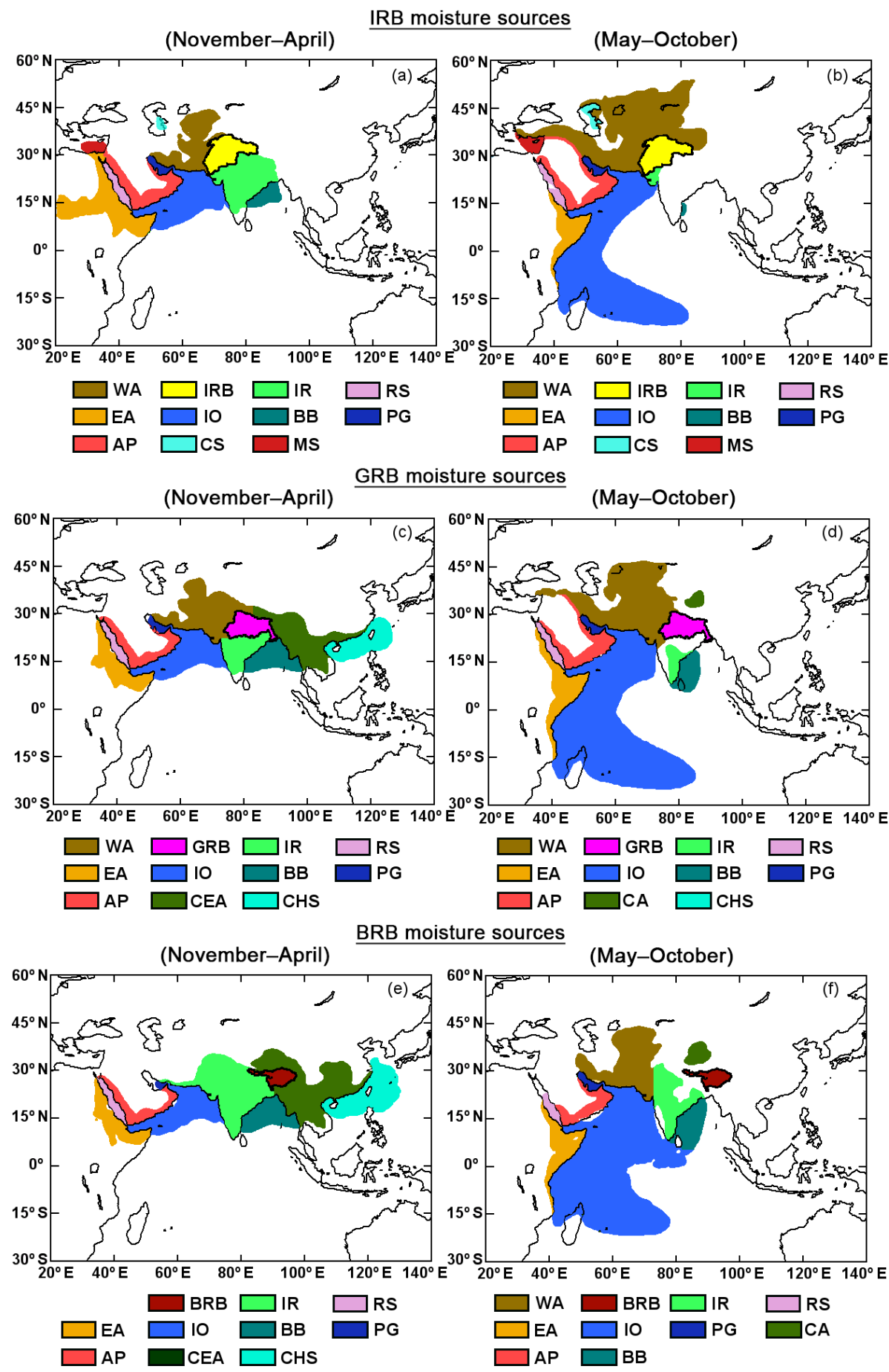

Figure 4. Schematic representation of the IRB (a and b), GRB (c and $\mathbf{d}$ ), and BRB (e and $\mathbf{f}$ ) moisture sources delimited by the p90 value shown in Fig. 3 for the WPR (left column) and MPR (right column). The acronyms identifying the moisture sources are defined in the text.

the recycled moisture. Because the GRB and BRB occur in both the continental and oceanic sources, the budget of the $(E-P) i 10$ remains positive (Fig. 5a). For the GRB, the positive $(E-P) i 10$ over the continental sources is greater than previously obtained for the IRB and the BRB, but less than that obtained over the oceanic moisture sources of the IRB.
Finally, the $(E-P) i 10$ over the BRB and its continental and oceanic sources are positive but less than previously computed over the moisture source regions of IRB and GRB. During the WPR in the GRB and the BRB, as occurred in the IRB, the PET is greater than $P$ and coincides with evaporative conditions in the atmospheric column over them. 

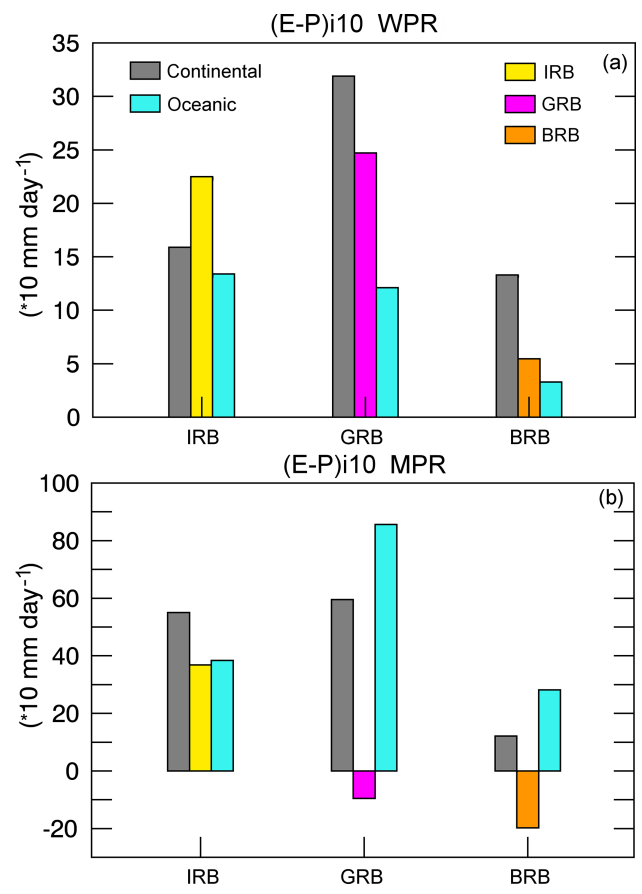

Figure 5. Total budget of $(E-P)$ integrated over 10 days in air masses tracked backward in time from the basins, over continental sources, oceanic sources, and the basins themselves. For the WPR (November-April) and the MPR (May-October) in the period 1981-2015.

The budget of $(E-P) i 10$ was also obtained from the moisture sources delimited by p90 for the MPR (Fig. 5b). In this period, as was previously discussed, the moisture sources are mostly larger, like those that occur in the Indian Ocean or western Asia (Fig. 3), and this could be reflected in the budget of $(E-P) i 10$. Like in the WPR, the atmospheric moisture budget is positive but greater over continental than oceanic sources and the IRB itself, which confirms the results of Fig. 2 which shows that PET is greater than $P$ over this basin in the entire year. These results indicate the increase of freshwater inputs to the basins due to continental evaporation (or recycling of moisture advected to the continents from remote regions). According to van der Ent et al. (2010), the continental evaporation recycling ratio is overall very high in Eurasia, which confirms that almost all of the continental evaporation returns to the continent, which can be seen from 50 to $100 \%$, especially over China, which depends on its water resources almost entirely from terrestrial evaporation from the Eurasian continent. These findings confirm our results. The $(E-P) i 10$ values in the air masses, tracked backward in time from the GRB and BRB, reveal a negative budget over GRB and BRB themselves (greatest for the BRB), which reflects that they act as an average moisture sink for humidity on air masses residing over them. In our approach, the resulting positive (negative) values of the moisture budget indicate moisture uptake, $E>P$ (for sinks,
$E<P)$; however, as we do the interpretation of the water balance and not the single evaporation or precipitation values, it could increase both $E$ and $P$ but one more than the other. Indeed, in this season, the $P$ exceeds the PET in both the GRB and BRB (Fig. 2b and c). In contrast, over the other terrestrial and oceanic sources of these basins, the budget is positive, which highlights the major amount of moisture uptake over the oceanic sources. Applying the water accounting model described by van der Ent et al. (2010) and van der Ent and Savenije (2011), Nikoli et al. (2012) also found that among the nine global river basins studied on an annual scale, the Indus River basin shows the highest increase in evaporation, but due to the land-use change, the Ganges-Brahmaputra shows the highest precipitation increase (of continental origin).

\subsubsection{Moisture contribution to precipitation $((E-P)<0)$}

The moisture contribution $((E-P)<0)$ from the sources to precipitation over the basins was obtained in a forward analysis over 10 days with FLEXPART. The percentage of moisture contribution from the IRB moisture sources (defined in Fig. 5) and the IRB itself appears in Fig. 6a. In both periods the WPR and the MPR, the IRB itself, the IO, and WA are the most important sources of moisture. The IR is also an important source for this basin in the WPR. In Fig. 6a it can be seen that the percentage of moisture supplied from continental sources represents a major percentage in both periods under study, although, in the MPR, the IO (38\%) is the second most important source after the IRB itself (42\%). To summarize these results, we calculated the seasonal average of $|(E-P) i 10<0|$ from all of the continental and oceanic sources. To understand these averages it must be noted that basin's areas are not spatially of the same size; they were calculated at $1^{\circ}$ in longitude and latitude.

The results confirm that terrestrial sources and overall the IRB itself can be responsible for the largest average moisture input to this basin (Fig. 6b). This result may seem erroneous because of the very well-known role of the Indian Ocean as a source of moisture for the Indian monsoon. However, it must be understood that the moisture transported from the Indian Ocean contributes to precipitation processes throughout Asia, and once it precipitates, it can evaporate and precipitate over the region and become the recycling that is fundamental to understanding this process. Karim and Veizer (2002) revealed that evapotranspiration is the major route for the loss of water from the IRB. As well as this, as river discharges fall short of reaching the sea during certain periods of the year, it is considered a closed basin (Molle et al., 2010). Thus, this increases the important role of evapotranspiration of natural vegetation and crops across the basin.

The same analysis performed in the air masses tracked forward in time from the GRB reveals that continental sources are the most important during the WPR for this basin, and 

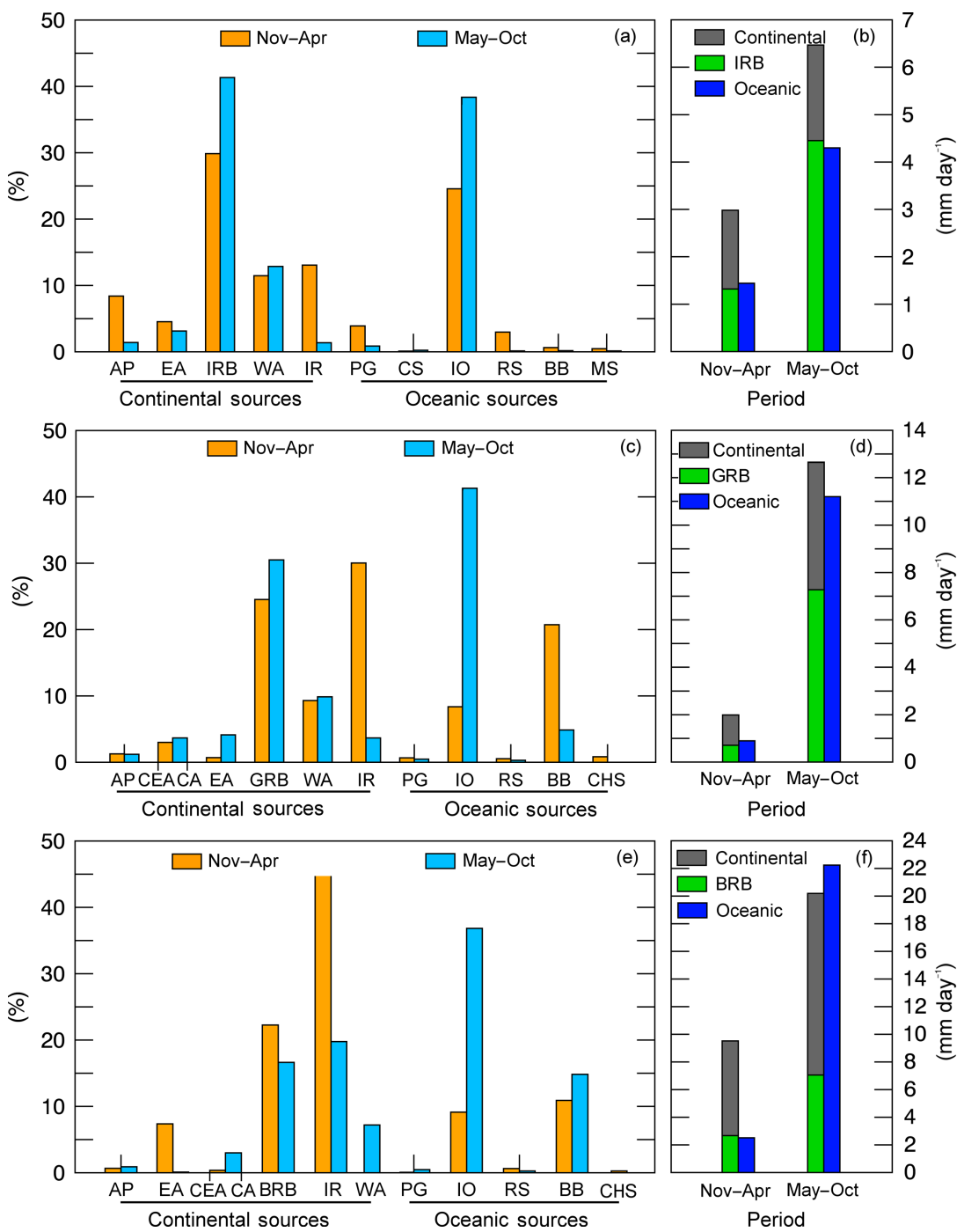

Figure 6. (Left panels) The percentage of moisture contributions $(|(E-P) i 10<0|)$ from the moisture sources to the IRB (a), GRB (c), and BRB (e) during November-April (WPR) (orange bars) and May-October (MPR) (blue bars) (right panels). The average moisture contribution from continental sources (grey bars), the IRB (b), GRB (d), BRB (f) (green bars), and oceanic sources (dark blue bars).

among these, the most important are the IR, GRB, and the WA (Fig. 6c). Among the oceanic sources, the most important in this season are the BB and IO. In the MPR, the IO provides more than the $40 \%$ of the total atmospheric moisture influx to the GRB, which is followed by the GRB itself $(32 \%)$. The average moisture loss (contributing to precipitation) over the GRB in the WPR from continental sources is greater than oceanic (Fig. 6d) sources and the MPR; however, in both periods, the moisture contribution from the oceanic sources is greater than those occurring over the GRB in air masses residing over itself. Indeed, the GRB is responsible for less than $1 \mathrm{~mm} \mathrm{day}^{-1}$ of moisture loss over itself in the WPR. In the MPR, the average contribution from all of the continental sources (including the GRB) is $12.8 \mathrm{~mm} \mathrm{day}^{-1}$, whereas from the oceanic sources, the contributions are less at approximately $11 \mathrm{~mm} \mathrm{day}^{-1}$. As the monsoon progresses through India, enhanced soil moisture and vegetation cover lead to increased evapotranspiration and recycled precipitation, which makes it possible for north-eastern India to have the highest recycling ratio (approximately $25 \%$ ) (Pathak et al., 2014). Specifically, within the Ganges basin, the fraction of evaporation that ends up as precipitation is approximately 50-60\% accordingly to Tuinenburg et al. (2012).

For the Brahmaputra basin, the most important moisture sources in the WPR are the IR and the BRB itself, BB and IO. In this period, the moisture supply from the IR to the BRB represents the $48 \%$ of the total moisture loss and this indicates that local moisture recycling must be favoured in this period (Fig. 6e). Indeed, it is shown in Fig. 6e that continental sources are responsible for a major percentage of the moisture loss over the BRB in the WPR. Overall, for the MPR, the $\mathrm{IO}$ is the most important moisture source and is responsible 
for approximately $37 \%$ of the total moisture loss over BRB. The BB is the second most important oceanic source while the rest of the oceanic sources are minimally important (even the CHS, which only appears in this season). The IR, BRB, and WA are among the continental moisture sources that are the most important in this period. An average of the total moisture loss over the BRB, calculated as the contribution from oceanic and land-based moisture sources and including the BRB, appears in Fig. 6f. In the WPR, the major role of the continental regions as moisture sources for the BRB is clear, but in May-October, the average $|(E-P) i 10<0|$ is greater in air masses arriving at the basin from the oceanic sources $\left(\sim 22 \mathrm{~mm} \mathrm{day}^{-1}\right)$. Nevertheless, there is not much difference from that computed in air masses with the continental origin.

Gimeno et al. (2010) observed that the Red Sea source provides vast amounts of moisture that precipitate between the Gulf of Guinea and the region of China and India in JuneAugust. As well as this, Pathack et al. (2017) noted that a significant fraction of atmospheric moisture to the ISM rainfall comes from five main moisture sources: the western Indian Ocean, central Indian Ocean, upper Indian Ocean, Ganges basin, and Red Sea and its neighbouring gulf. In agreement with the previous findings, we obtained that the Red Sea and the Persian Gulf act as sources of moisture for the Indus, Ganges, and Brahmaputra river basins. Nevertheless, in our analysis we considered them separated (unlike Pathack et al., 2017), obtaining a negligible role from each one to the total moisture contribution mainly for the GRB and BRB in both the WPR and MPR.

It may be confusing that the total contribution to precipitation from continental sources is a little greater than from ocean sources for the IRB and GRB in the MPR (Fig. 6b, d), contrary to the results of Pathack et al. (2017) for the Indian region (which mostly comprises the GRB). Differences may arise because the method is used to calculate the moisture contribution, even when both are based on a Lagrangian approach. In particular, Pathack et al. (2017) implemented an extension of the Dynamic Recycling Model (DRM) developed by Domínguez et al. (2006) and modified by Martinez and Dominguez (2014). Their method permit quantification of the relative contributions from different sources to the atmospheric moisture over a given sink region, by calculating the fraction of atmospheric moisture collected by an air column along its trajectory between times considering the evaporation and the precipitable water, respectively, along the two-dimensional trajectory. With the aim of clarifying this, we calculated the climatological daily accumulated anomalies of moisture contribution from the sources (from FLEXPART) and the precipitation over them (from CHIRPS) along with the MPR, which is of utmost importance because of the monsoon influence. This analysis on a daily scale permits an understanding of the temporal relationship variability between the contribution of moisture from the sources to the precipitation (rapid increase \& decrease) over the basins within the MPR.
For the IRB, the minimum rainfall-accumulated anomalies occur on 23 June (Fig. 7a), and from this date onwards the rainfall-accumulated anomalies are increased until 9 September. At the beginning of June, the moisture supply to this basin was enhanced first by IO and later by WA and the IRB itself. The accumulated anomalies on the contribution by the rest of the continental and oceanic sources occur after the abrupt rainfall increase over the basin and do not represent great changes to the amount of humidity according to low anomalies (Fig. 7a and b). Before the maximum accumulated anomaly of precipitation (on 9 September), it is possible to observe a decay of accumulated anomalies of $|(E-P) i 10<0|$ values from the basin itself after the second half of August. A decrease of anomalies in the WA's contribution starts less abruptly and a few days before the decay of the rainfall anomalies. From the beginning of the second half of August, the accumulated anomalies of moisture supply from the IO to the IRB starts to decrease; however, an abrupt decay is not clearly seen after it occurs for the precipitation.

Accumulated anomalies on the moisture contribution from the IO to the GRB during the first days of June reach the minimum value and then immediately increase rapidly (before the contribution from the rest of the sources); later, on June 15, the minimum value of rainfall-accumulated anomalies occurs over the basin (Fig. 7c). In fact, from the rest of oceanic sources, these values are mostly positive during all of the MPR and do not surpass $50 \mathrm{~mm} \mathrm{day}^{-1}$. At the beginning of the second half of August, the accumulated anomalies from the IO reach almost $500 \mathrm{~mm}$ day $^{-1}$, which confirms the huge amount of moisture transported from this source to the GRB. A day later, as previously commented, the precipitation anomaly falls and reflects a time response between moisture input to the basin from the IO and a rainfall decrease over it. These results show that the most significant amount of moisture to the GRB first comes from the IO, and the results of Fig. $6 \mathrm{~d}$ must be explained by the moisture recycling process over the continental sources of the GRB and/or a minor residence time of the water vapour over the continent, which influences the budget of $(E-P)$. Among the continental sources, the accumulated anomalies of the contribution of moisture from the basin itself at the beginning showed a similar cycle to the precipitation-accumulated anomalies, but later reach maximum values in the middle of August, days before 16 September, when the rainfall actually reaches this point. From the rest of the continental sources, the annual cycle of accumulated anomalies reflects less similarity than the rainfall. These results confirm that although the total moisture input to the GRB during the MPR is greater from continental sources than from oceanic (Fig. 6d), the IO plays a crucial primary role in the hydrological cycle for the monsoonal precipitation onset over this basin, in agreement with Pathack et al. (2014, 2017), who highlight the key role of the IO on the ISM and the role of land surface processes in the generation of precipitation within the Indian sub-continent. 


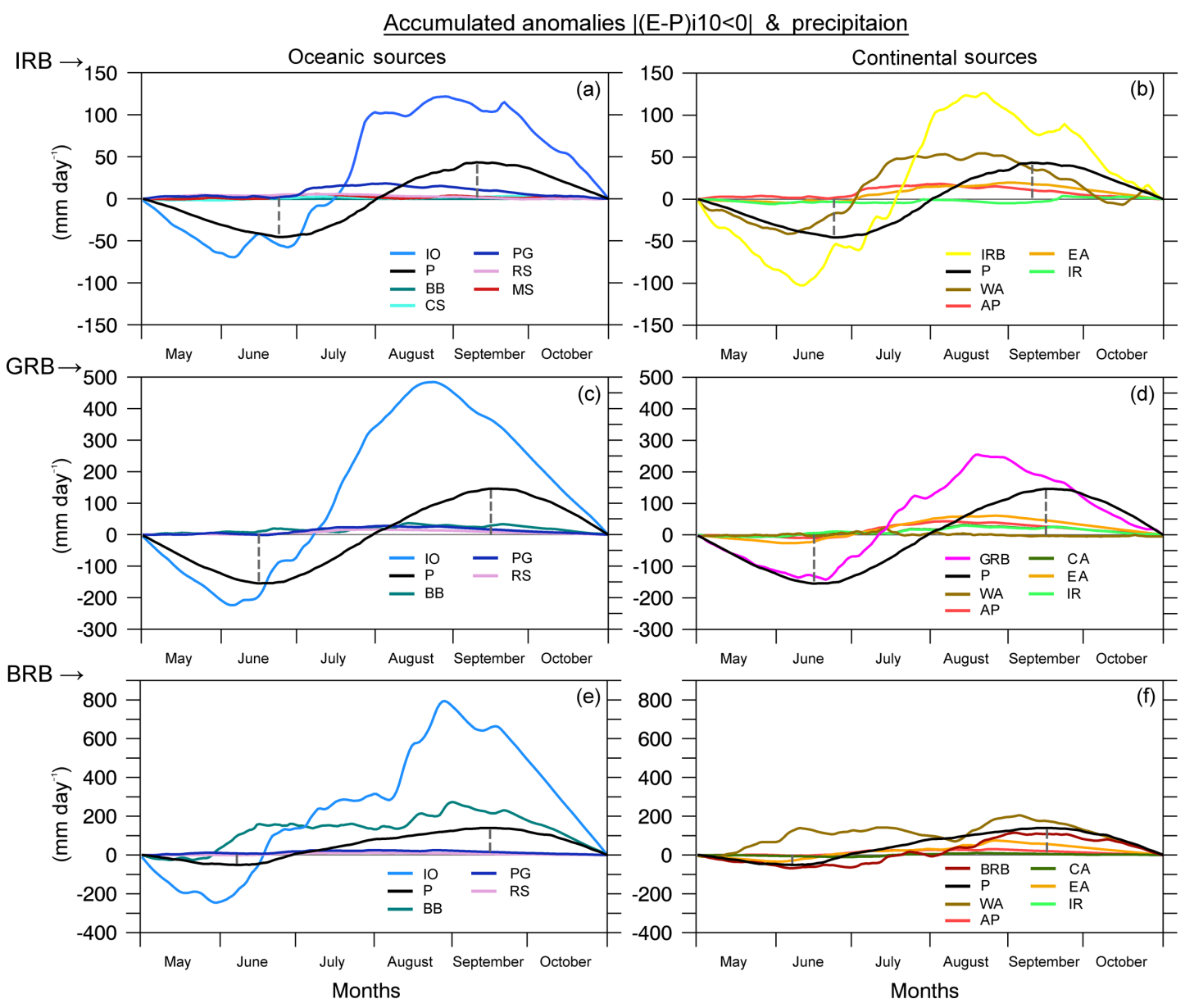

Figure 7. Daily accumulated anomalies of $|(E-P) i 10<0|$ values computed over each basin on air masses forward in time and tracked from the oceanic sources (left panels), continental sources (right panels) (the colour of the lines are in accordance with the name of the sources in Fig. 5), and precipitation (red line) from CHIRPS.

Over the BRB, the seasonal accumulated anomaly of rainfall reaches a minimum on 7 June (Fig. 7e). However, before this date and around mid-May minimum values also occur in the accumulated anomalies of the moisture contribution from the BB and later at the end of May from the IO. After this, the moisture supply starts to increase from these. Before the rainfall decay on 13 September (1 day after maximum rainfallaccumulated anomalies), the moisture contribution decreases first from the IO and later from the BB towards the end of $\mathrm{Au}$ gust. Both sources (as was discussed) are the main oceanic moisture sources for the BRB. From the continental sources of accumulated anomalies, the majority follow the accumulated anomaly of precipitation except for the moisture input from WA, which is positive after the first days of May. Nevertheless, this region is not the most important continental source of moisture for the BRB.

Correlations were calculated between the total $\mid(E-$ $P) i 10<0 \mid$ values computed from all of the sources and separately for the $P$ and PET in the basins for the WPR and MPR. Significant $r$ values only appear in Fig. 8. As expected, con- sidering the annual cycle of the $P$ and PET at the basins, we obtained positive correlations between $|(E-P) i 10<0|$ and $P$ and negative correlations for $|(E-P) i 10<0|$ and PET. For the IRB in the WPR, the best positive correlations $(r>0.60)$ are for the moisture input to the basin from the IO with precipitation, followed by significant $r$ values also obtained with the contribution from the RS, PG, AP, and the IRB itself. The moisture loss over the IRB is oppositely correlated with PET in this basin, and only the moisture supply from the BB is not significantly correlated with the PET. In the MPR, the only positive significant correlations were obtained for the precipitation and the moisture influx from EA, IRB itself, IR, and IO. For the monsoon season, no correlation was significant between PET and $|(E-P) i 10<0|$, which indicates that there is not a statistically direct relationship during the MPR.

The correlations for the WPR and MPR in the GRB were expressed like that for the IRB and showed positive (negative) and statistically significant correlations for $P$ and $|(E-P) i 10<0|($ PET and $|(E-P) i 10<0|)$. In the WPR, 

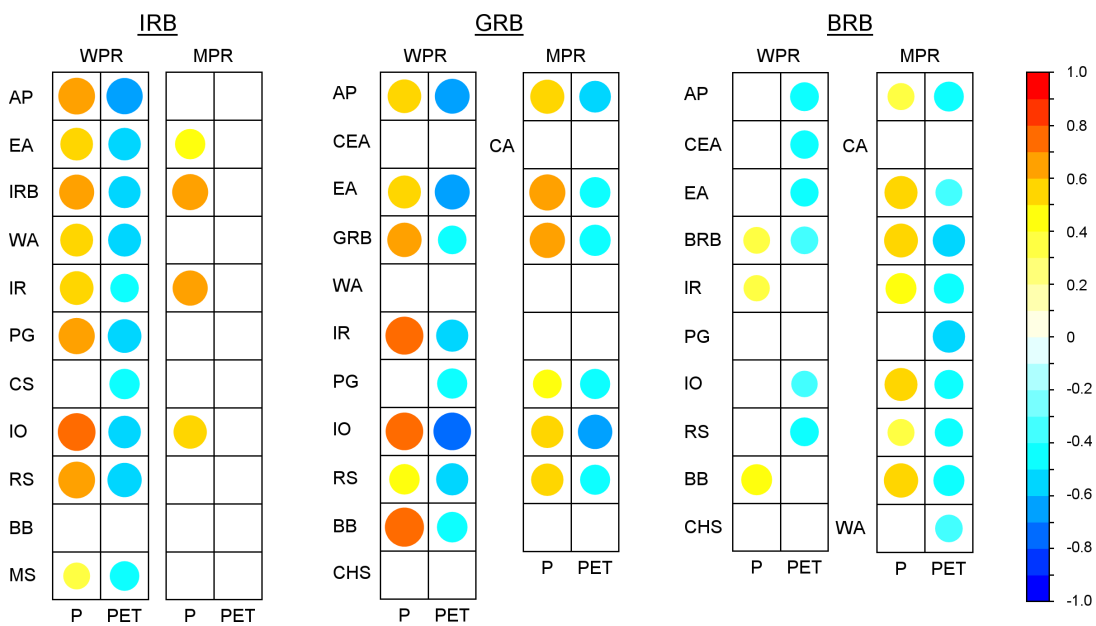

Figure 8. Monthly correlations (statistically significant at $p<0.05$ ) for the WPR (November-April) and MPR (May-October) periods between precipitation and potential evapotranspiration $(P, \mathrm{PET}$; from CRU) with total (summed average contributions from all the sources) $|(E-P) i 10<0|$ over each basin (from FLEXPART).

the positive feedback occurred for the series from the IO, BB, and IR with $\mathrm{P}$, while the greatest negative correlations are for the IO, EA, and AP with PET. Some correlations are not significant: for example, for the moisture contribution from the CHS, WA, and CEA in WPR and from BB, IR, WA, and CA in the MPR. For the BRB, the analysis showed a contrast from the previous findings and few low and significant correlations for the moisture contribution from the BB, IR, and the basin itself with the precipitation over this basin in the WPR. The PET and $|(E-P) i 10<0|$ correlations were negative for most of the cases in this period. In the monsoonal period, as seen in Fig. 8, the $r$ values indicate the best correlation of both $P$ and PET with $|(E-P) i 10<0|$ from the basin itself and from the BB and IO, which are the two most important oceanic sources for the BRB.

A climatological analysis of the North American monsoon system (NAMS) precipitation recycling reveals a positive feedback mechanism between monsoon precipitation and a subsequent increase in the precipitation of a recycled origin (Domínguez et al., 2008). For the wettest NAMS monsoons, Bosilovich et al. (2003) documented that the evaporation and soil wetness time series tends to track similarly to the precipitation. In the Gangetic Plain and north-eastern India, a significant amount of precipitation also comes from precipitation recycling (Pathak et al., 2014). For example, for the GRB and at the initial phase of the monsoon, the Indian Ocean is a strong moisture source and the subsequent recharge of soil moisture makes the evapotranspiration over the Ganges basin become active after the onset of the monsoon (Pathak et al., 2017). Despite these results, we found negative correlations between the moisture contribution to the basins and the PET on them, which suggests the need for a monthly analysis to determine whether or not it occurs on a minor or major temporal scale.

\subsection{Variability of $(E-P)$ during the SAM onset and the demise over the basins}

We calculated the budget of $(E-P) i 10$ in air masses tracked backward in time from each basin at days $-1,-4,-7$, and -10 before the rainfall increase (decrease) associated with the SAM onset (demise) over the IRB, GRB, and BRB. To determine the onset and demise dates, we applied an objective index from Noska and Misra (2016) for the basins, which is based on the cumulative anomalies of averaged daily rainfall (see Eqs. 4 and 5). To illustrate the method, Fig. 9 shows the daily average precipitation from CHIRPS (Chris et al., 2015) over the GRB in 2010 and the cumulative anomalies. The cumulative anomalies reached the minimum value on 15 June and the maximum on 22 September. For this year, the rainfall associated with the monsoon onset occurred on 16 June and ends on 22 September over the GRB. Observation indicates that the daily precipitation rate changes occur abruptly for the onset and demise, which agrees with similar findings for different regions across the Indian region and South East Asia (e.g. Ananthakrishnan and Soman, 1988; Soman and Kumar, 1993; Cook and Buckley, 2009).

By applying Eqs. (4) and (5), it was possible to obtain the onset and demise dates of precipitation associated with the monsoonal influence for every year. These dates are represented in Fig. 10 and it is possible to observe that rainfall associated with the SAM onset starts first at the BRB (commonly in May), later the GRB (commonly in June), and finally at the IRB (commonly in June, and some cases in July) (Fig. 10a). In contrast, the precipitation decline because of the SAM demise occurs first over the IRB, followed by the GRB and the BRB (Fig. 10b), which indicates that the length of the monsoonal rainy season at the IRB is shorter than over the GRB and both were shorter than over the BRB. This re- 


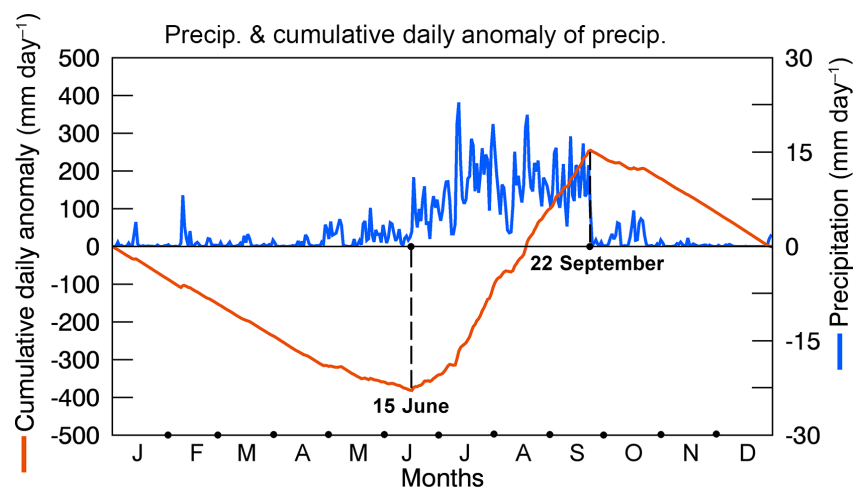

Figure 9. Daily precipitation (blue line) and the cumulative daily anomaly of the precipitation (orange line) (from CHIRPS) over the GRB during 2010. 15 June (22 September) represents the minimum (maximum) cumulative daily anomaly of the precipitation.

veals that from the east to the west the onset of monsoon rainfall takes longer to occur. A climatology of the length of the summer monsoon season (in days) obtained by Misra and DiNapoli (2014) also reflects that over the region of the BRB the number of days between the onset and demise is greater than in regions to the west (where the GRB and IRB are located) and where the length decreases longitudinally. Similar onset and retreat dates were obtained by Hasson et al. (2016) but utilizing a distinct method on a CMIP5 climate model's data for observational and future periods.

A composite of the days for the monsoonal rainfall onset and demise over each basin was performed. Utilizing each composite, the budget of $(E-P)$ for days $-1,-4,-7$, and -10 was calculated before the onset and demise; this way, it was possible to determine the spatial changes of moisture uptake by air masses in travel to the basins. One day backward in time from the onset at the IRB, air masses uptake humidity over the basin itself and the surrounding regions (Fig. 11). At day -4 , air masses arriving at the IRB uptake humidity from the western Indian Ocean, the Arabian Sea, the Persian Gulf, the continental regions to the west of the basin and the basin itself. Over the north-eastern Arabian Sea, a remarkable change from conditions of pre-monsoon onset days was also described by Howland and Sikdar (1983) when the specific humidity increased as much as $5 \mathrm{~g} \mathrm{~kg}^{-1}$ from premonsoon to monsoon onset. At days -7 and -10 , the pattern of $(E-P)$ is more extended with positive values (moisture uptake) mainly to the west of the basin, part of the Arabian Sea and the western Indian Ocean. Particles arrive at the IRB losing humidity from over the south and South East Asia and the Bay of Bengal.

Analysing the $(E-P)$ pattern for the pre-demise, at day -1 it is very similar to the same day before the onset; however, in the centre and north-east of the basin appear $(E-P)<0$ areas, which indicates the prevalence of moisture loss. At day -4 , areas with $(E-P)>0$ seem to occupy less than on day -4 of the pre-onset, whereas more parcels arrive at the basin after losing humidity (according to the greater spatial extension of areas of $(E-P)<0)$. At days -7 and -10 of the pre-demise, the main differences on the $(E-P)$ pattern (with respect to the same days for the pre-onset) are over the basin, and greater $(E-P)>0$ values are apparent over the Arabian Sea at day -10 where moisture uptake is major for the pre-demise. This is because days before the demise there should be major precipitation and consequently greater moisture uptake for the basin.

One day backward in time from the monsoonal rainfall onset over the GRB, the air masses over this basin gain humidity almost over the entire basin itself, but to the east is a moisture sink, which in contrast covers practically the entire basin at day -1 from the rainfall demise of this basin. At day -4 from the onset and on the budget of $(E-P)$, the positive values are very intense for mainly those over the basin itself, to the west of the basin, over India, the Arabian Sea, and part of the Bay of Bengal. For the days before the onset, the positive values in the field of $(E-P)$ are more restricted in the northern part of the Arabian Sea, which suggests this region plays a key role in the monsoonal rainfall onset but also the demise over the GRB. The negative values (moisture sink) are more intense to the east of the GRB before the demise (as expected). For the pattern of $(E-P)$ at days -7 and -10 from the onset, the WA and IO play as crucial role in providing humidity to this basin, and their sources contribute for the same dates before the demise; however, the eastern part of the basin (on average) behaves as a moisture sink and $(E-P)>0$ values are more restricted to the north of the budget pattern.

For the GRB, the results of the backward experiment highlight that at day -1 from the onset this basin acts as a moisture sink for the region as a whole. On this day, the $(E-P)$ reveals that air parcels arrive at the basin and gain humidity just from a small region to the south-west of the basin. The pattern is very similar at day -1 from the demise but $(E-P)>0$ values are not located to the north-east of the basin. These results are not surprising since, from the Fig. 2 results, we understand that for the MPR the water balance over the BRB suggests that $P$ exceeds $E$ in the budget. At day -4 of the onset, the basin uptake humidity from the west, the Indian region, and the western part of the Bay of Bengal is visually noticeable. However, the $(E-P)$ pattern completely changed for the day -4 from the demise, which shows that air masses arrive at the BRB and gain and transport moisture from the west and north of the basin and from the small regions in the north-eastern Arabian Sea and the Bay of Bengal. Furthermore, moisture loss prevails in air masses travelling to the BRB from the south and when remaining over itself. At days -7 and -10 , the spatial pattern of $(E-P)$ is quite similar for the pre-onset and pre-demise with the most remarkable difference over the south-east of Asia, the Bay of Bengal, and the BRB itself due to the moisture loss prevalence. 

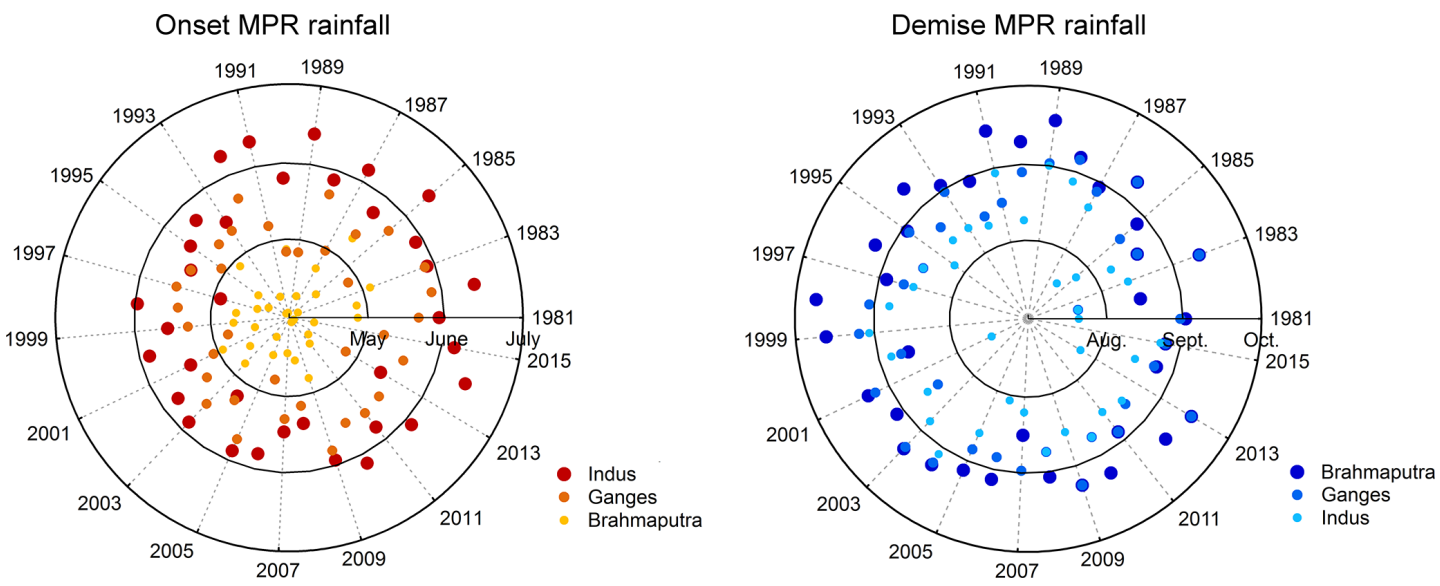

Figure 10. Onset and demise of the monsoonal rainfall for the Indus, Ganges, and Brahmaputra river basins.

\subsection{Moisture contribution during the dry and wet conditions in the basins}

The SPEI was utilized to identify dry and wet conditions at the IRB, GRB, and BRB. The temporal evolution of this index on the temporal scale of 6 months is shown in Fig. 12. We identify dry conditions at the IRB from 1998 to 2002 and increasing wet conditions from 2011 to 2015 . A drought-intensive period in Pakistan was identified by Xie et al. (2013) for the late 1990s to early 2000s, in agreement with our results. Pakistan is mostly located within the IRB, and hence, the hydrological condition of the basin regulated those of the country. In the GRB during the 2000-2010 decade, dry conditions were very frequent, whereas in the BRB dry conditions mainly occurred in 1981-1986, 2003-2010, and 2012-2015 (Fig. 12). Kumar et al. (2013) documented that short-term drought (SPEI6) over the Indian region is characterized by strong periodicity on quasi-biennial ( $2-4$ years) and decadal (12-16 year) timescales.

We use the 6-month SPEI at the end of October (April) to diagnose dry and wet conditions at the basins over the MPR (WPR) season. We selected those seasons under severe and extremely dry and wet conditions according to SPEI6 values (Tables 1 and 2), and the anomalies on the moisture contribution $(|(E-P) i 10<0|)$ from each moisture source to the basins were calculated by creating composites of the WPR and MPR affected by severe and extremely dry and wet conditions. The SPEI6 was also utilized for the same purposes by Drumond et al. (2016) to investigate drought episodes in the climatological sinks of the Mediterranean moisture source.

Common dry WPR occurred at the IRB and BRB in 2001 and at the GRB and the BRB in 1999. According to SPEI $>1.5$ values, severe and extreme wet WPR seasons occurred at the IRB in 2015 and 1983 (Table 1). In 2015, it was also severely wet in the GRB (as well as in 1982) and extremely so in 1998, whereas at the BRB, just two seasons were classified as severely wet (2007 and 2010). In the period from
Table 1. WPR under severe and extremely dry and wet conditions at the Indus, Ganges, and Brahmaputra river basins during the period from 1981 to 2015 .

\begin{tabular}{lrlrlr}
\hline $\begin{array}{l}\text { Dry } \\
\text { Date }\end{array}$ & IRB & & GRB & BRB \\
April 2001 & -1.64 & April 1999 & -1.55 & April 2001 & -1.72 \\
& & April 2009 & -2.25 & April 2014 & -1.88 \\
& & & & April 1999 & -1.88 \\
\hline Wet & & & & & \\
\hline April 2015 & 1.51 & April 1982 & 1.78 & April 2007 & 1.69 \\
April 1983 & 2.0 & April 2015 & 1.89 & April 2010 & 1.92 \\
& & April 1998 & 2.0 & & \\
\hline
\end{tabular}

1981 to 2015 , there were three severely dry MPR periods at the IRB and also three for the GRB, but one of them was extremely dry (2014) (Table 2). For the BRB, despite being the wettest basin, four MPR are characterized under severely dry conditions and of these, the WPR of 2005 accounted for both the GRB and the BRB. During the wettest MPR periods (Table 2), the greatest number of cases occurred at the GRB as well, and all were severely wet (like the two periods in the BRB), whereas at the IRB, of the two wet periods only one was extremely wet in 2010 .

The moisture contribution negative anomalies for the WPR dry composites at the IRB are evidence of the major deficit in the moisture supply from the IR, the IRB itself, and the IO (Fig. 13a, orange bars); the same sources are responsible for greatest positive moisture loss anomalies for the wettest WPR (Fig. 13a, green bars). For the MPR, the anomalies in the moisture input to the IRB during dry periods occur mainly from two sources, the IO and the own IRB. This indicates that during the monsoonal season under dry conditions, as it rains less over the basin it will not favour the precipitation over itself but could for remote regions. For the wettest MPR, the opposite occurs. 

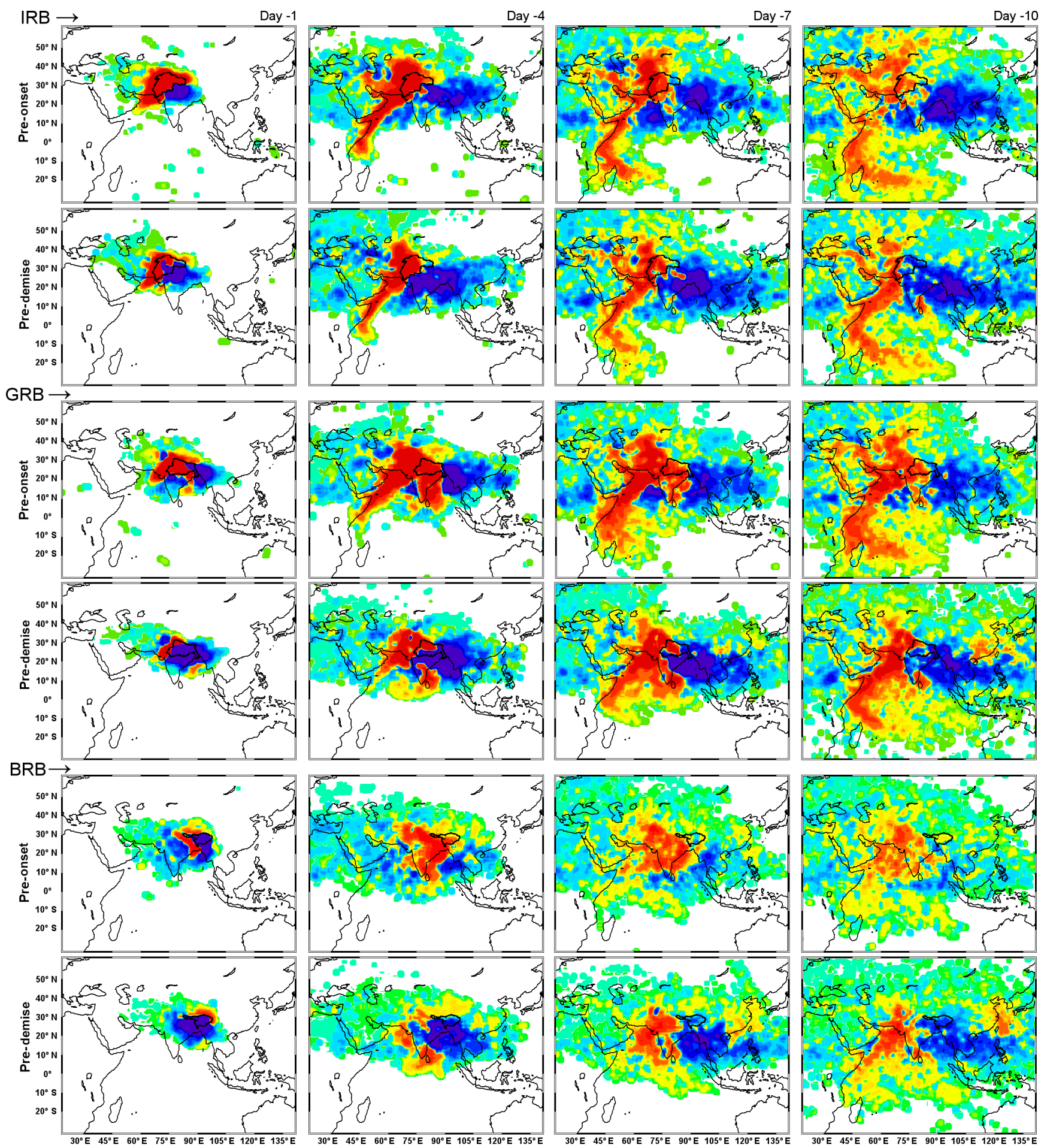

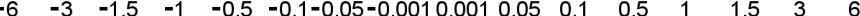

(E-P)i10 (mm day $\left.{ }^{-1}\right)$

Figure 11. Composite of $(E-P)$ in a backward experiment from the IRB for a composite of days $-1,-4,-7$, and -10 from the onset and demise of the monsoon. 

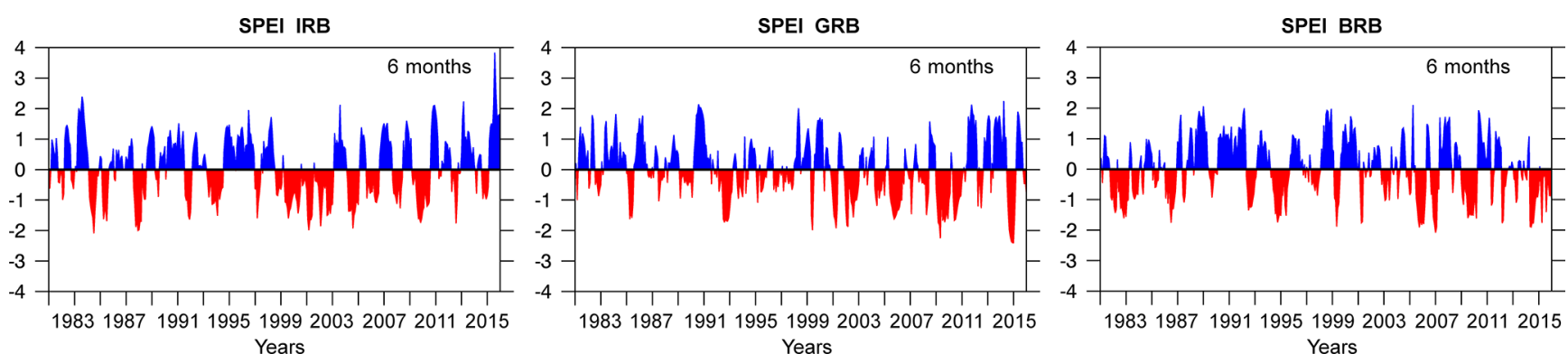

Figure 12. Monthly SPEI for a timescale of 6 months averaged for the Indus, the Ganges, and Brahmaputra river basins in the period from 1981 to 2015.

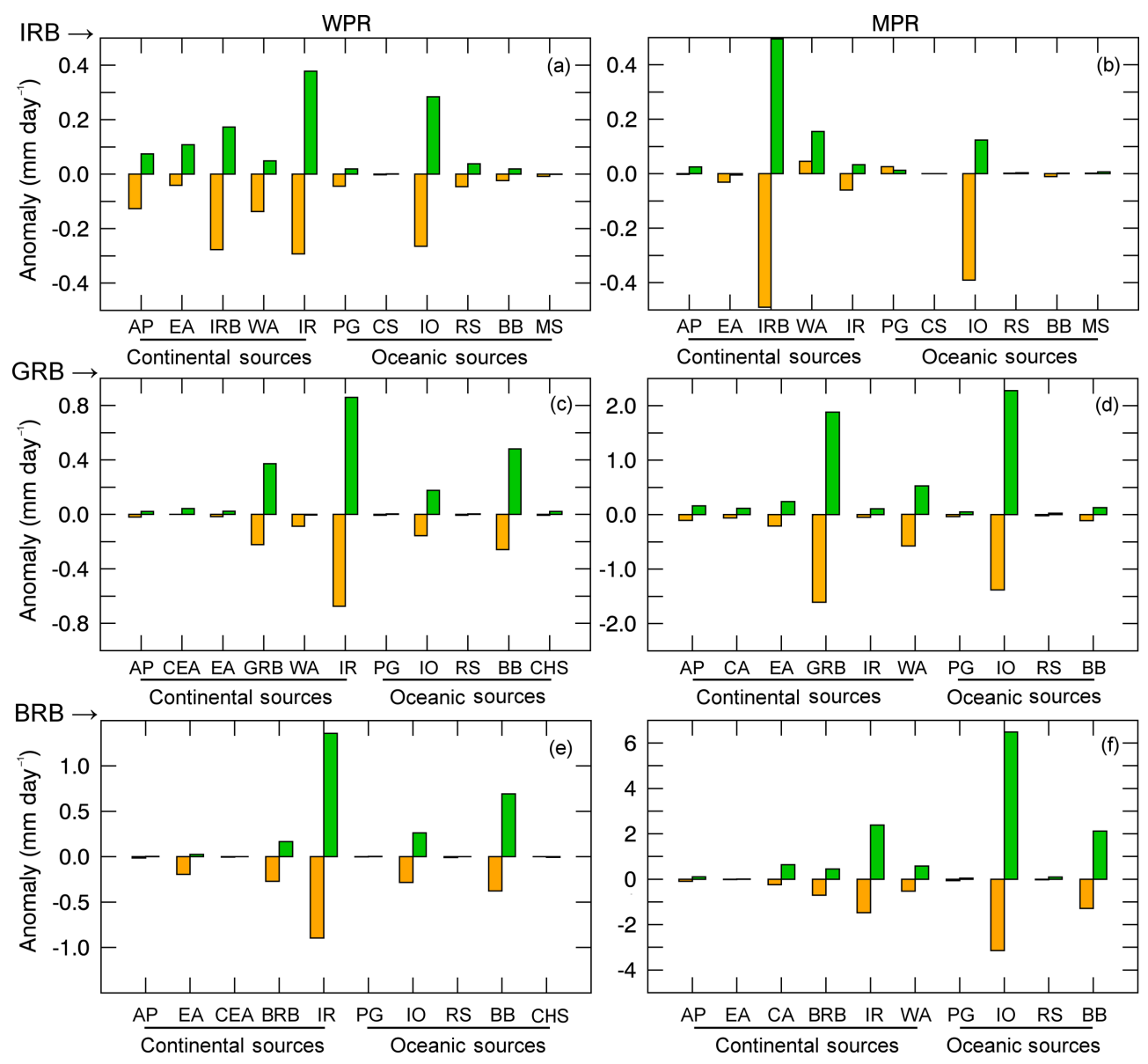

Figure 13. Anomalies of the moisture contribution $(|(E-P) i 10<0|)$ from each source to the IRB, GRB, and BRB during severe and extremely dry and wet condition at the basins (orange and green bars, respectively) from the period of 1981-2015.

In the GRB, the driest WPRs are associated with negative anomalies of moisture supply mainly from two continental moisture sources, IR and the basin itself, and two oceanic sources, BB and IO (Fig. 13c, orange bars). The same sources are responsible for positive anomalies during the wettest WPRs (green bars). This means that during the WPR months, severely and extremely dry and wet conditions are regulated in the GRB by anomalies of the moisture supply from the surrounding land regions (mainly to the south over India), the Bay of Bengal and less from the IO and the GRB itself. For MPR, the greatest negative anomalies of the $|(E-P) i 10<0|$ values over the GRB in the composite of the dry conditions occur in air masses arriving at the basin from itself, the IO, and WA, whereas for wettest periods the highest positive anomalies are on the moisture inputs to the GRB from the same sources: the IO, followed by the GRB itself and WA. These anomalies allow confirmation that the wettest periods in the GRB are related to an increase of the moisture 
Table 2. MPR under severe and extremely dry and wet conditions at the Indus, Ganges, and Brahmaputra river basins during the period from 1981 to 2015.

\begin{tabular}{lrlrlr}
\hline $\begin{array}{l}\text { Dry } \\
\text { Date }\end{array}$ & IRB & & GRB & & BRB \\
\hline October 1991 & -1.51 & October 2005 & -1.56 & October 1994 & -1.58 \\
October 1987 & -1.62 & October 1992 & -1.68 & October 2006 & -1.60 \\
October 2009 & -1.74 & October 2014 & -2.35 & October 2005 & -1.60 \\
& & & & October 1982 & -1.61 \\
\hline Wet & & & & & \\
\hline October 2015 & 1.75 & October 1999 & 1.62 & October 1998 & 1.56 \\
October 2010 & 2.08 & October 2013 & 1.65 & October 1988 & 1.72 \\
& & October 2011 & 1.83 & & \\
& & October 1990 & 1.92 & & \\
\hline
\end{tabular}

supply from the IO, and the local contribution is surely enhanced because of moisture recycling, which is a mechanism well explained for the GRB by Tuinenburg et al. (2012).

In the BRB during the WPR as well as for the GRB, the $\mathrm{IR}, \mathrm{BB}, \mathrm{IO}$, and the basin itself are the regions from where a reduction of moisture supply to the BRB drastically occurs during the driest November-April periods (Fig. 13e, orange bars) and the moisture supply increases during the wettest periods (green bars). In the MPR, the IO becomes the source from which the atmospheric transport that contributes to precipitation over the BRB experiment shows the highest reduction during the driest periods $\left(<3 \mathrm{~mm} \mathrm{day}^{-1}\right)$ (Fig. 13f, orange bar) and the maximum increase for the wettest periods $\left(>6 \mathrm{~mm} \mathrm{day}^{-1}\right.$ ) (Fig. 13f, green bar). The BB is the second most important oceanic source in terms of the anomalies, whereas the IR is the most important among the terrestrial sources. For almost all of the cases when dry (wet) conditions occur at the basins, negative (positive) anomalies occur for the moisture contribution to precipitation, which is generally from all of the sources over the basins. As precipitation depends on the amount of water vapour in the atmosphere, the most important anomalies in the contribution from these sources highlight the main aspects responsible for drought and intense precipitation over the basins.

\section{Conclusions}

The 3-dimensional model FLEXPART was used to track backward in time the air masses residing over the IRB, GRB, and BRB. The model permitted the calculation of the budget of evaporation minus precipitation $(E-P)$ along backward and forward trajectories integrated over 10 days and allowed the identification of the climatological moisture sources of each basin for the westerly precipitation regime (NovemberApril) and monsoonal precipitation regime (May-October) over 35 years (1981-2015). The results indicate that moisture sources are positioned in continental and oceanic regions as well as the basins themselves. Their spatial extension increases during the MPR (when the rainfall is highest over the basins) and principally in the Indian Ocean. Along each trajectory, the budget of $(E-P)$ over most evaporative continental and oceanic sources was calculated, which revealed the importance of moisture uptake for the basins over continental regions during the WPR. A forward analysis performed from the sources revealed the important role of continental regions on the average moisture contribution to precipitation over the IRB and GRB during the MPR and during which the oceanic sources are the most important for the BRB. However, during the MPR, the greatest moisture contribution to precipitation over the basins occurs from the IO, except for the IRB, where local moisture losses in $(E-P)$ play a dominant role. Additionally, the IO seems to be responsible for first providing moisture to the basins in the MPR period and is linked to the rapid rainfall increase or decrease. Generally, the most important moisture sources for the IRB, GRB, and BRB are the western Asia extension, the Indian region, the Indian Ocean, the Bay of Bengal and the basins themselves. A spatial analysis of the resulting $(E-P)$ pattern in the pre-onset and pre-demise of the monsoonal precipitation over each basin exposed the spatial differences mainly on the moisture uptake variability and confirmed the spatial reduction mainly of the evaporative source in the IO days before the demise.

As expected, the average moisture (summed $(E-P)<0$ from all the sources) loss over the basins' values integrated over 10 days is positively correlated with the precipitation and negatively correlated with the potential evapotranspiration even during the MPR, when some studies suggest that both variables increase. The roles of the sources in the moisture contribution to precipitation during severe and extremely dry and wet conditions at the basins were assessed through WPR and MPR composites, and confirmed the crucial role of those most important moisture sources (eg. IR, IO, BB, and the basins themselves) in providing less (more) humidity during dry (wet) conditions in both periods WPR and MPR. Even though the hydrological cycle over the Asian region has been widely investigated, the results obtained here will also support further climate research, but specifically over the IRB, GRB, and BRB. Future research would be an important contribution to investigating the influence of the modes of climate variability, principally ENSO, on the modulation of moisture transport from the sources of moisture to the basins.

Data availability. The ERA-Interim datasets are freely available at https://www.ecmwf.int/ (Dee et al., 2011). The precipitation and potential evapotranspiration data from CRU TS v3.24.01 (Harris et al., 2014) can be downloaded at http://www.cru.uea.ac.uk/data. The daily precipitation data from CHIRPS are available from http: //chg.geog.ucsb.edu/data/chirps/ (Chris et al., 2015). The model FLEXPART (Stohl and James, 2004, 2005) can be freely downloaded (https://www.flexpart.eu/) and utilized. For FLEXPART results, please contact Raquel Nieto (rnieto@uvigo.es). 
Competing interests. The authors declare that they have no conflict of interest.

Special issue statement. This article is part of the special issue "The changing water cycle of the Indo-Gangetic Plain". It is not associated with a conference.

Acknowledgements. This work was supported by EPhysLab (UVIGO-CSIC associated unit). Rogert Sorí would like to acknowledge the grant received by the Xunta of Galicia, Spain, in support of his doctoral research work. Raquel Nieto acknowledges the support provided by CNPq grant 314734/2014-7 from the Brazilian government. Anita Drumond acknowledges the support of the Spanish Government and FEDER via the SETH (CGL201460849-JIN) project. The authors thank the Water Works 2014 co-funded call of the European Commission, which financed the IMDROFLOOD project. This research was partially supported by Xunta de Galicia under project ED413C 2017/64 "Programa de Consolidación y Estructuración de Unidades de Investigacion Competitivas (Grupos de Referencia Competitiva)" co-funded by European Regional Development Fund (FEDER).

Edited by: Pradeep P. Mujumdar

Reviewed by: Vasu Misra and one anonymous referee

\section{References}

Ananthakrishnan, R. and Soman, M. K.: The onset of the southwest monsoon over Kerala: 1901-1980, J. Climatol., 8, 283-296, 1988.

Berrisford, P., Kållberg, P., Kobayashi, S., Dee, D., Uppala, S., Simmons, A. J., Poli, P., and Sato, H.: Atmospheric conservation properties in ERA-Interim, Q. J. Roy. Meteor. Soc., 137, 13811399, https://doi.org/10.1002/qj.864, 2011.

Bisselink, B. and Dolman, A. J.: Precipitation Recycling: Moisture Sources over Europe using ERA-40 Data, J. Hydrometeorol., 9, 1073-1083, https://doi.org/10.1175/2008JHM962.1, 2008.

Bosilovich, M. G., Sud, Y. C., Schubert, S. D., and Walker, G. K.: Numerical simulation of the large-scale North American monsoon water sources, J. Geophys. Res., 108, 8614, https://doi.org/10.1029/2002JD003095, 2003.

Castillo, R., Nieto, R., Drumond, A., and Gimeno, L.: Estimating the Temporal Domain when the Discount of the Net Evaporation Term Affects the Resulting Net Precipitation Pattern in the Moisture Budget Using a 3-D Lagrangian Approach, PLoS ONE, 9, e99046, https://doi.org/10.1371/journal.pone.0099046, 2014.

Ceglar, A., Toreti, A., Balsamo, G., and Kobayashi, S.: Precipitation over Monsoon Asia: A Comparison of Reanalyses and Observations, J. Climate, 17, 465-476, 2017.

Cheema, M. J. M.: Understanding water resources conditions in data scarce river basins using intelligent pixel information, Case: Transboundary Indus Basin, PhD thesis, TU Delft, University Delft, the Netherlands, 209 pp., 2012.

Chen, B., Xu, X.-D., Yang, S., and Zhang, W.: On the origin and destination of atmospheric moisture and air mass over the Tibetan Plateau, Theor. Appl. Climatol., 110, 423-435, https://doi.org/10.1007/s00704-012-0641-y, 2012.

Chris, F., Peterson, P., Landsfeld, M., Pedreros, D., Verdin, J., Shukla, S., Husak, G., Rowland, J., Harrison, L., Hoell, A., and Michaelsen, J.: The climate hazards infrared precipitation with stations - a new environmental record for monitoring extremes, Scientific Data 2, 150066, https://doi.org/10.1038/sdata.2015.66, 2015 (data available at: http://chg.geog.ucsb.edu/data/chirps, last access: 1 May 2017).

COLA: The Center for Ocean-Land-Atmosphere Studies, available at: http://cola.gmu.edu/wcr/river/basins.html, last access: 2 February 2017.

Cook, B. I. and Buckley, B. M.: Objective determination of monsoon season onset, withdrawal, and length, J. Geophys. Res., 114, D23109, https://doi.org/10.1029/2009JD012795, 2009.

Davis, T.: Agricultural water use and river basin conservation, A World Wide Fund For Nature (WWF) Summary Report, 2003.

Dee, D. P., et al.: The ERA-Interim reanalysis: Configuration and performance of the data assimilation system, Q. J. Roy. Meteor. Soc., 137, 553-597, https://doi.org/10.1002/qj.828, 2011 (data available at: https://www.ecmwf.int/, last access: 1 May 2017).

Dhar, O. N. and Nandargi, S.: A study of floods in the Brahmaputra basin in India, Int. J. Climatol., 20, 771-781, 2000.

Dimri, A. P., Niyogi, D., Barros, A. P., Ridley, J., Mohanty, U. C., Yasunari, T., and Sikka, D. R.: Western Disturbances: A review, Rev. Geophys., 53, 225-246, https://doi.org/10.1002/2014RG000460, 2015.

Domínguez, F., Kumar, P., Liang, X.-Z., and Ting, M..: Impact of atmospheric moisture storage on precipitation recycling, J. Climate, 19, 1513-1530, https://doi.org/10.1175/JCLI3691.1, 2006.

Domínguez, F., Kumar, P., and Vivoni, E. R.: Precipitation Recycling Variability and Ecoclimatological Stability - A Study Using NARR Data. Part II: North American Monsoon Region, J. Climate, 5187-5203, https://doi.org/10.1175/2008JCLI1760.1, 2008.

Drumond, A., Nieto, R., and Gimeno, L.: Sources of moisture for China and their variations during drier and wetter conditions in 2000-2004: a Lagrangian approach, Clim. Res., 50, 215-225, https://doi.org/10.3354/cr01043, 2011.

Drumond, A., Marengo, J., Ambrizzi, T., Nieto, R., Moreira, L., and Gimeno, L.: The role of the Amazon Basin moisture in the atmospheric branch of the hydrological cycle: a Lagrangian analysis, Hydrol. Earth Syst. Sci., 18, 2577-2598, https://doi.org/10.5194/hess-18-2577-2014, 2014.

Drumond, A., Gimeno, L., Nieto, R., Trigo, R. M., and Vicente-Serrano, S. M.: Drought episodes in the climatological sinks of the Mediterranean moisture source: The role of moisture transport, Global Planet. Change, 151, 4-14, https://doi.org/10.1016/j.gloplacha.2016.12.004, 2016.

Durán-Quesada, A. M., Gimeno, L., Amador, J. A., and Nieto, R.: Moisture sources for Central America: Identification of moisture sources using a Lagrangian analysis technique, J. Geophys. Res., 115, D05103, https://doi.org/10.1029/2009JD012455, 2010.

Eltahir, E. A. B. and Bras, R. L.: Precipitation recycling, Rev. Geophys., 34, 367-378, https://doi.org/10.1029/96RG01927, 1996.

Gadgil, S.: The Indian Monsoon and its variability, Annu. Rev. Earth Planet. Sci., 31, 429-467, https://doi.org/10.1146/annurev.earth.31.100901.141251, 2003. 
Gimeno, L.: Grand challenges in atmospheric science, Front. Earth Sci., 1, 1-5, https://doi.org/10.3389/feart.2013.00001, 2014.

Gimeno, L., Drumond, A., Nieto, R., Trigo, R. M., and Stohl, A.: On the origin of continental precipitation, Geophys. Res. Lett., 37, L13804, https://doi.org/10.1029/2010GL043712, 2010.

Gimeno, L., Stohl, A., Trigo, R. M., Dominguez, F., Yoshimura, K., Yu, L., Drumond, A., Durán-Quesada, A. M., and Nieto, R.: Oceanic and terrestrial sources of continental precipitation, Rev. Geophys., 50, RG4003, https://doi.org/10.1029/2012RG000389, 2012.

Gong, C. and Eltahir, E. A. B.: Sources of Moisture for Rainfall in West Africa, Water Resour. Res., 32, 3115-3121, 1996.

Harris, I., Jones, P. D., Osborn, T. J., and Lister, D. H.: Updated high-resolution grids of monthly climatic observations - the CRU TS3.10 Dataset, Int. J. Climatol., 34, 623-642, https://doi.org/10.1002/joc.3711, 2014 (data available at: http: //www.cru.uea.ac.uk/data, last access: 1 May 2017).

Hasson, S., Lucarini, V., and Pascale, S.: Hydrological cycle over South and Southeast Asian river basins as simulated by PCMDI/CMIP3 experiments, Earth Syst. Dynam., 4, 199-217, https://doi.org/10.5194/esd-4-199-2013, 2013.

Hasson, S., Lucarini, V., Pascale, S., and Böhner, J.: Seasonality of the hydrological cycle in major South and Southeast Asian river basins as simulated by PCMDI/CMIP3 experiments, Earth Syst. Dynam., 5, 67-87, https://doi.org/10.5194/esd-5-67-2014, 2014.

Hasson, S., Pascale, S., Lucarini, V., and Böhner, J.: Seasonal cycle of Precipitation over Major River Basins in South and Southeast Asia: A Review of the CMIP5 climate models data for present climate and future climate projections, Atmos. Res., 180, 42-63, 2016.

Hossen, M. A.: The Ganges Basin management and community empowerment, Bandung: Journal of the Global South, 2, 14, https://doi.org/10.1186/s40728-014-0005-3, 2015.

Howland, M. R. and Sikdar, D. N.: The moisture budget over the Northeastern Arabian Sea during Premonsoon and Monsoon onset, 1979, Mon. Weather Rev., 11, 2255-2268, 1983.

Huang, Y. and Cui, X.: Moisture sources of an extreme precipitation event in Sichuan, China, based on the Lagrangian method, Atmos. Sci. Lett., 16, 177-183, https://doi.org/10.1002/as12.562, 2015.

Immerzeel, W. W. and Bierkens, M. F. P.: Seasonal prediction of monsoon rainfall in three Asian river basins: the importance of snow cover on the Tibetan Plateau, Int. J. Climatol., 30, 18351842, 2010.

Janowiak, J. E. and Xie, P.: A Global-Scale Examination of Monsoon-Related Precipitation, J. Climate, 16, 4121-4133, 2003.

Jian, J., Webster, P. J., and Hoyos, C. D.: Large-scale controls on Ganges and Brahmaputra river discharge on intraseasonal and seasonal time-scales, Q. J. Roy. Meteor. Soc., 135, 353-370, https://doi.org/10.1002/qj.384, 2009.

Karim, A. and Veizer, J.: Water balance of the Indus River Basin and moisture source in the Karakoram and western Himalayas: Implications from hydrogen and oxygen isotopes in river water, J. Geophys. Res., 107, 4362, https://doi.org/10.1029/2000JD000253, 2002.

Katerji, N. and Rana, G.: Crop Reference Evapotranspiration: A Discussion of the Concept, Analysis of the Process and Validation, Water Resour. Manag., 25, 1581-1600, 2011.
Kumar, K. N., Rajeevan, M., Pai, D. S., Srivastava, A. K., and Preethi, B.: On the observed variability of monsoon droughts over India, Weather and Climate Extremes, 1, 42-50, 2013.

Laghari, A. N., Vanham, D., and Rauch, W.: The Indus basin in the framework of current and future water resources management, Hydrol. Earth Syst. Sci., 16, 1063-1083, https://doi.org/10.5194/hess-16-1063-2012, 2012.

Lehner, B., Verdin, K., and Jarvis, A.: New global hydrography derived from spaceborne elevation data, Eos, Transactions, AGU, 89, 93-94, 2008.

Levine, R. C. and Turner, A. G.: Dependence of Indian monsoon rainfall on moisture fluxes across the Arabian Sea and the impact of coupled model sea surface temperature biases, Clim. Dynam., 38, 2167-2190, https://doi.org/10.1007/s00382-011-1096z, 2012.

Liebmann, B., Carmargo, S. J., Seth, A., Marengo, J. A., Carvalho, L. M. V., Allured, D., Fu, R., and Vera, C. S.: Onset and end of the rainy season in South America in observations and the ECHAM 4.5 atmospheric general circulation model, J. Climate, 20, 2037-2050, 2007.

Lorenz, C. and Kunstmann, H.: The hydrological cycle in three state-of-the-art reanalyses: Intercomparison and performance analysis, J. Hydrometeorol., 13, 1397-1420, 2012.

Mahanta, C., Zaman, A. M., Newaz, S. M. S., Rahman, S. M. M., Mazumdar, T. K., Choudhury, R., Borah, P. J., and Saikia, L.: Physical Assessment of the Brahmaputra River, International Union for Conservation of Nature (IUCN), Dhaka, Bangladesh, ISBN-13: 978-984-91041-8-6, 2014.

Marathayil, D., Turner, A. G., Shaffrey, L. C., and Levine, R. C.: Systematic wintersea-surface temperature biases in the northern Arabian Sea in HiGEM and the CMIP3 models, Environ. Res. Lett., 8, 014028, https://doi.org/10.1088/1748-9326/8/1/014028, 2013.

Martinez, J. A. and Dominguez, F.: Sources of atmospheric moisture for the La Plata River basin, J. Climate, 27, 6737-6753, https://doi.org/10.1175/JCLI-D-14-00022.1, 2014.

McKee, T. B., Doesken, N. J., and Kliest, J.: The relationship of drought frequency and duration to time scales, Proceedings of the 8th Conference on Applied Climatology, 17-22 January, Anaheim, CA, American Meteorological Society, Boston, MA, 179184, 1993.

McVicar, T. R., Michael, L. R., Donohue, R. J., Li, L. T., Van Niel, T. G., Thomas, A., Grieser, J., Jhajharia, D., Himri, Y., Mahowald, N. M., Mescherskayai, A. V., Krugerj, A. C., Rehman, S., and Dinpashoh, Y.: Global review and synthesis of trends in observed terrestrial near-surface wind speeds: Implications for evaporation, J. Hydrol., 416-417, 182-205, 2012.

Misra, V. and DiNapoli, S.: The variability of the Southeast Asian summer monsoon, Int. J. Climatol., 34, 893-901, https://doi.org/10.1002/joc.3735, 2014.

Misra, V., Pantina, P., Chan, S. C., and DiNapoli, S.: A comparative study of the Indian summer monsoon hydroclimate and its variations in three reanalyses, Clim. Dynam., 39, 1149, https://doi.org/10.1007/s00382-012-1319-y, 2012.

Molle, F., Wester, P., and Hirsch, P.: River basin closure: Processes, implications and responses, Agr. Water Manage., 97, 569-577, https://doi.org/10.1016/j.agwat.2009.01.004, 2010. 
Nieto, R., Gimeno, L., and Trigo, R. M.: A Lagrangian identification of major sources of Sahel moisture, Geophys. Res. Lett., 33, $1-6,2006$.

Nikoli, R., van der Ent, R. J., Savenije, H. H. G., Hoff, H., and Waha, K.: Moisture recycling and the effect of land-use change, Master Thesis, TU Delft University, the Netherlands, 2012.

Noska, R. and Misra, V.: Characterizing the onset and demise of the Indian summer monsoon, Geophys. Res. Lett., 43, 4547-4554, https://doi.org/10.1002/2016GL068409, 2016.

Numaguti, A.: Origin and recycling processes of precipitating water over the Eurasian continent: Experiments using an atmospheric general circulation model, J. Geophys. Res., 104, 1957-1972, 1999.

Ordoñez, P., Ribera, P., Gallego, D., and Peña-Ortiz, C.: Major moisture sources for Western and Southern India and their role on synoptic-scale rainfall events, Hydrol. Process., 26, 3886-3895, https://doi.org/10.1002/hyp.8455, 2012.

Pathak, A., Ghosh, S., and Kumar, P.: Precipitation recycling in the Indian subcontinent during summer monsoon, J. Hydrometeorol., 15, 2050-2066, https://doi.org/10.1175/JHM-D-13-0172.1, 2014.

Pathak, A., Ghosh, S., Martínez, J. A., Domínguez, F., and Kumar, P.: Role of Oceanic and Land Moisture Sources and Transport in the Seasonal and Interannual Variability of Summer Monsoon in India, J. Climate, 30, 1839-1859, https://doi.org/10.1175/JCLID-16-0156.1, 2017.

Peixoto, J. P. and Oort, A. H.: Physics of Climate, New York, Springer-Verlag New York Press, United States, 1992.

Qiao, Y., Wu, R., Huang, W., and Jian, M.: Interannual variability of moisture source over southern Indian Ocean during boreal summer and its relationship with local SST, Int. J. Climatol., 33, 556-567, https://doi.org/10.1002/joc.3445, 2013.

Qureshi, M. T.: Water Management in the Indus Basin in Pakistan: Challenges and Opportunities, Mt. Res. Dev., 31, 252-260, 2011.

Rajagopalan, B. and Molnar, P.: Signatures of Tibetan Plateau heating on Indian summer monsoon rainfall variability, J. Geophys, Res.-Atmos., 118, 1170-1178, https://doi.org/10.1002/jgrd.50124, 2013.

Ramage, C. S.: Monsoon Meteorology. Academic Press, New York and Lodon, 296 pp., 1971.

Rasul, G.: Water for growth and development in the Ganges, Brahmaputra, and Meghna basins: an economic perspective, International Journal of River Basin Management, 13, 387-400, https://doi.org/10.1080/15715124.2015.1012518, 2015.

Sebastian, D. E., Pathak, A., and Ghosh, S.: Use of Atmospheric Budget to Reduce Uncertainty in Estimated Water Availability over South Asia from Different Reanalyses, Sci. Rep., 6, 29664, https://doi.org/10.1038/srep29664, 2016.

Slingo, J.: The Indian summer monsoon and its variability, in: Beyond El Niño: Decadal Variability in the Climate System, edited by: Navarra, A., Springer-Verlag, 103-118, 1999.

Soman M. K. and Kumar, M. K.: Space-time evolution of Meteorological Features-associated with the onset of Indian summer monsoon, Mon. Weather Rev., 121, 1177-1194, 1993.

Song, J.-H., Kang, H.-S., Byun, Y.-H., and Hong, S.-Y.: Effects of the Tibetan Plateau on the Asian summer monsoon: a numerical case study using a regional climate model, Int. J. Climatol., 30, 743-759, https://doi.org/10.1002/joc.1906, 2010.
Stohl, A. and James, P.: A Lagrangian analysis of the atmospheric branch of the global water cycle. Part I: Method description, validation, and demonstration for the August 2002 flooding in central Europe, J. Hydrometeorol., 5, 656-678, https://doi.org/10.1175/15257541(2004)005<0656:ALAOTA>2.0.CO;2, 2004.

Stohl, A. and James, P.: A Lagrangian analysis of the atmospheric branch of the global water cycle. Part II: Moisture transports between the Earth's ocean basins and river catchments, J. Hydrometeorol., 6, 961-984, https://doi.org/10.1175/JHM470.1, 2005.

Taniguchi, K. and Koike, T.: Comparison of definitions of Indian summer monsoon onset: Better representation of rapid transitions of atmospheric conditions, Geophys. Res. Lett., 33, L02709, https://doi.org/10.1029/2005GL024526, 2006.

Tare, V., Roy, G., and Bose, P.: Ganga River Basin Management Plan. Main document, Indian Institutes of Technology of Bombay, Delhi, Guwahati, Kanpur, Kharagpur, Madras, Roorkee, 2015.

Trenberth, K. E.: Atmospheric Moisture Recycling: Role of Advection and Local Evaporation, J. Climate, 12, 1368-1380, 1999.

Tuinenburg, O. A., Hutjes, R. W. A., and Kabat, P.: The fate of evaporated water from the Ganges basin, J. Geophys. Res., 117, D01107, https://doi.org/10.1029/2011JD016221, 2012.

van der Ent, R. J. and Savenije, H. H. G.: Length and time scales of atmospheric moisture recycling, Atmos. Chem. Phys., 11, 18531863, https://doi.org/10.5194/acp-11-1853-2011, 2011.

van der Ent, R. J., Savenije, H. H. G., Schaefli, B., and Steele-Dunne, S. C.: Origin and fate of atmospheric moisture over continents, Water Resour. Res., 46, 1-12, https://doi.org/10.1029/2010WR009127, 2010.

Vicente-Serrano, S. M., Berguería, S., and López-Moreno, J. I.: A Multiscalar Drought Index Sensitive to Global Warming: The Standardized Precipitation Evapotranspiration Index, J. Climate, 23, 1696-1718, https://doi.org/10.1175/2009JCLI2909.1, 2010.

Webster, P. J.: The coupled monsoon system, in: The Asian Monsoon, edited by: Mason, J., Springer-Verlag Berlin Heidelberg, New York, USA, 3-66, https://doi.org/10.1007/3-540-377220_1, 2006.

Xie, H., Ringler, C., Zhu, T., and Waqas, A.: Droughts in Pakistan: a spatiotemporal variability analysis using the Standardized Precipitation Index, Water Int., 38, 620-631, https://doi.org/10.1080/02508060.2013.827889, 2013.

Yanai, M. and Wu, G.: Effects of the tibetan plateau, in: The Asian Monsoon, edited by: Wang, B., Springer Berlin Heidelberg, 514 549, 2006.

Yatagai, A., Arakawa, O., Kamiguchi, K., Kawamoto, H., Nodzu, M. I., and Hamada, A.: A 44-year daily precipitation dataset for Asia based on dense network of rain gauges, SOLA, 5, 137-140, https://doi.org/10.2151/sola.2009-035, 2009.

Yoon, J.-H. and Huang, W.-R.: Indian Monsoon Depression: Climatology and Variability, in: Modern Climatology, edited by: Wang, S.-Y., InTech, 45-73, 2012.

Zeng, X. and Lu, E.: Globally Unified Monsoon Onset and Retreat Indexes, J. Climate, 17, 2241-2248, 2004. 